\title{
Survival and recurrence after acute pulmonary embolism treated with pulmonary embolectomy or thrombolysis in New York State, 1999 to 2013
}

Timothy Lee, BS, ${ }^{a}$ Shinobu Itagaki, MD, MS, ${ }^{a}$ Yuting P. Chiang, MD, MS, ${ }^{b}$ Natalia N. Egorova, PhD, David H. Adams, MD, and Joanna Chikwe, MD $^{\mathrm{a}, \mathrm{d}}$

\section{ABSTRACT}

Background: Pulmonary embolism (PE) results in more than 250,000 hospitalizations annually in the United States, with high mortality. Outcome data are limited, and reperfusion strategies remain controversial. Here we evaluated the outcomes of thrombolysis and surgical embolectomy in patients with acute PE using a statewide database.

Methods: Among 174,322 patients hospitalized with PE in New York State between 1999 and 2013, we performed a retrospective comparison of 2111 adults with acute PE who underwent either thrombolysis $(n=1854 ; 88 \%)$ or surgical embolectomy $(\mathrm{n}=257 ; 12 \%)$ as first-line therapy. Patients were identified using a mandatory database. The median follow-up was 4.2 years (range, $0-16.3$ years). The primary study endpoint was all-cause mortality; secondary outcomes included recurrent PE, recurrent deep vein thrombosis, reintervention, and stroke.

Results: In 2111 patients who underwent reperfusion, there was no difference in 30-day mortality between those who underwent thrombolysis and those who underwent surgical embolectomy $(15.2 \%$ vs $13.2 \%$; odds ratio [OR], $1.12,95 \%$ confidence interval [CI], 0.72-1.73). Thrombolysis was associated with higher risk of stroke $(1.9 \%$ vs $0.8 \%$; OR, $4.70 ; 95 \% \mathrm{CI}, 1.08-20.42)$ and reintervention $(3.8 \%$ vs $1.2 \%$; OR, 7.16; 95\% CI, 2.17-23.62) at 30 days. Five-year actuarial survival was similar in the 2 groups $(72.4 \%$ [95\% CI, $70.3 \%-74.5 \%$ ] vs $76.1 \%$ [95\% CI, 70.2\%-81.0\%]; hazard ratio (HR) for death, $1.11 ; 95 \% \mathrm{CI}$, 0.83-1.49). Thrombolysis was associated with a higher rate of recurrent PE necessitating inpatient readmission $(7.9 \%$ [95\% CI, 6.9\%-9.4\%] vs $2.8 \%$ [95\% CI, $1.1 \%-5.8 \%$ ]; HR, 3.38; 95\% CI, 1.48-7.73).

Conclusions: Pulmonary embolectomy and thrombolysis are associated with similar early and long-term survival, supporting guideline recommendations for embolectomy when thrombolysis is contraindicated. (J Thorac Cardiovasc Surg

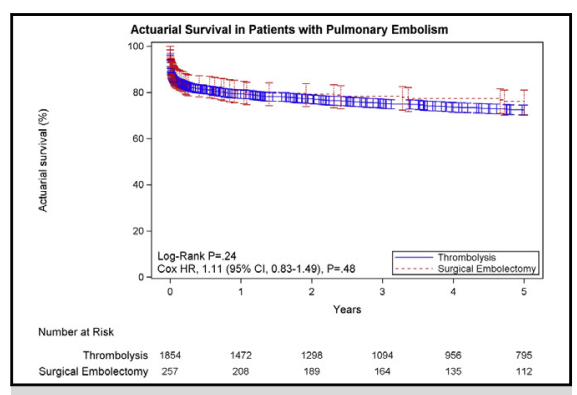

Actuarial survival after thrombolysis or surgical embolectomy in New York State, 1999 to 2013

\section{Central Message}

Pulmonary embolectomy is associated with similar early and long-term survival compared to thrombolysis, supporting guideline recommendations for embolectomy when thrombolysis is contraindicated.

\section{Perspective}

Pulmonary embolism results in more than 250,000 hospitalizations annually in the United States, with high mortality. Outcome data are limited, and choice of reperfusion strategy remains controversial. We provide the first multicenter data evaluating early and long-term outcomes after pulmonary embolectomy and thrombolysis.

See Editorial Commentaries pages 1091 and 1093.

See Editorial page 1080. 2018;155:1084-90)

From the Departments of a Cardiovascular Surgery and ${ }^{\mathrm{c}}$ Population Health Science and Policy, Icahn School of Medicine at Mount Sinai; ${ }^{b}$ Department of Surgery, Columbia University Medical Center, New York Presbyterian Hospital, New York; and ${ }^{\mathrm{d}}$ Division of Cardiothoracic Surgery, Department of Surgery, Stony Brook University Hospital, Stony Brook, NY.

Presented at the American College of Cardiology's 65th Annual Scientific Session and Expo, Chicago, Illinois, April 2-4, 2016.

Received for publication Oct 15, 2016; revisions received July 4, 2017; accepted for publication July 29, 2017; available ahead of print Sept 21, 2017.

Address for reprints: Joanna Chikwe, MD, Department of Cardiovascular Surgery, Mount Sinai Medical Center, 1190 Fifth Ave, New York, NY 10029 (E-mail: Joanna.Chikwe@mountsinai.org).

0022-5223/\$36.00

Copyright @ 2017 Published by Elsevier Inc. on behalf of The American Association for Thoracic Surgery

http://dx.doi.org/10.1016/j.jtcvs.2017.07.074
An estimated 186,000 to 270,000 adults are hospitalized with pulmonary embolism (PE) each year in the United States. ${ }^{1,2}$ The mainstay of treatment for sub-massive and massive PE is thrombolysis, which restores pulmonary perfusion faster than anticoagulation alone and is associated with a mortality

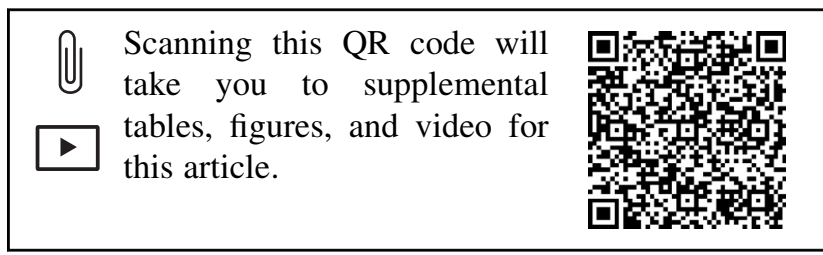




$$
\begin{aligned}
& \begin{array}{ll}
\text { Abbreviations and Acronyms } \\
\text { CI } & \text { confidence interval } \\
\text { HR } & \text { hazard ratio } \\
\text { ICD-9-CM = } & \text { International Classification of } \\
& \text { Diseases, Ninth Revision, Clinical } \\
& \text { Modification } \\
= & \text { inferior vena cava } \\
\text { IVC } & \text { odds ratio } \\
\mathrm{OR} & \text { pulmonary embolism }
\end{array}
\end{aligned}
$$

benefit. $^{3-5}$ For patients with contraindications to thrombolysis, surgical embolectomy may be indicated. ${ }^{4,5}$ Outcome data after surgical embolectomy are limited to small, single-center cohorts, with follow-up dependent on patients returning to the same institution. ${ }^{6-9}$ Consequently, survival and long-term morbidity, including recurrence of $\mathrm{PE}$, are not well defined. In the present study, we analyzed a statewide administrative database to quantify long-term mortality and morbidity including recurrent venous thromboembolism rates after PE treated with thrombolysis or surgical pulmonary embolectomy (Video 1).

\section{METHODS \\ Patients}

We conducted a retrospective cohort analysis comparing outcomes after thrombolysis or surgical embolectomy in New York State from January 1, 1999, through December 31, 2013, in adult patients (age $\geq 18$ years) diagnosed with acute PE. Patients were identified using the International Classification of Diseases, Ninth Revision, Clinical Modification (ICD-9-CM) diagnostic codes for PE (415.1x), and procedural codes for thrombolysis (99.10) or surgical embolectomy (38.05); both a diagnosis code for PE and a procedural code for thrombolysis or surgical embolectomy must have been present within the same admission. In addition, the patient must have been admitted with a primary diagnosis of PE and received treatment within 3 days of the admission date. Exclusion criteria were out-ofstate residency, planned admission, pulmonary endarterectomy on the same or earlier date as the index procedure, and inferior vena cava (IVC) filter placement before the index admission.

The cohort was identified using New York's Statewide Planning and Research Cooperative System, an all-payer administrative database that prospectively collects patient-level data on every hospital discharge, ambulatory surgery visit, and emergency department visit in the state. Baseline comorbidities were identified using ICD-9-CM diagnosis codes from the index hospitalizations and all hospitalizations up to 2 years before the index hospitalization. The annual incidence of PE was calculated by dividing the number of adults with first-time PE each year by the estimated adult population of New York State ${ }^{10}$ for that year.

This study was approved by the Data Protection Review Board of the New York State Department of Health as well as the Program for Protection of Human Subjects at the Icahn School of Medicine at Mount Sinai. The approval included a waiver of informed consent.

\section{Study Endpoints}

The primary outcome measure was all-cause mortality. Secondary outcomes were recurrent PE, recurrent deep vein thrombosis, reoperation or reintervention, stroke, major bleeding events, and administration of blood transfusions. Deaths were identified using the Social Security Death Master
File, and hospital, emergency room, and ambulatory surgery visits were also searched for any deaths not identified through the Social Security Death Master File. The final follow-up date for all-cause mortality was May 29, 2015.

Recurrent PE was defined as a diagnosis of a recurrent embolism that occurred during the index hospitalization or was identified during any subsequent inpatient or outpatient encounter; additional analysis focused on the recurrent events that necessitated inpatient readmission. Recurrent deep vein thrombosis was defined as any event identified during a subsequent inpatient or outpatient encounter. Reoperation or reintervention was defined as any surgical pulmonary embolectomy, thrombolysis infusion, or surgical pulmonary endarterectomy performed after the index procedure. Stroke was defined as any intracerebral hemorrhage or ischemic stroke occurring during the index hospital admission, or any subsequent hospital admission for which one of these events was the primary diagnosis; transient ischemic events were excluded. Major bleeding was defined as any intracerebral hemorrhage, gastrointestinal hemorrhage (including bleeding peptic ulcer), hemopericardium, cardiac tamponade, or iatrogenic postoperative bleed occurring during the index hospital admission, or any subsequent hospital admission for which one of these events was the primary diagnosis. The ICD-9-CM codes used for the study endpoints are listed in Table E1. Patients for whom no recurrent PE or date of death was found were censored on May 29, 2015.

\section{Statistical Analysis}

Continuous variables are reported as mean \pm standard deviation, and categorical variables are expressed as number and proportion. Differences in baseline characteristics between the thrombolysis and surgical cohorts were detected using the $t$ test for normally distributed continuous variables and the $\chi^{2}$ test for categorical variables.

The incidence of 30-day complications in the 2 treatment groups was compared using logistic regression analysis, incorporating all baseline characteristics (including year of surgery; age, sex, and race/ethnicity; history of deep vein thrombosis; history of PE, cancer, surgery, or trauma within 30 days of admission; known hypercoagulable state; major bleeding within 30 days of admission; ischemic stroke within 6 months of admission; known coagulopathy, cerebrovascular disease, peripheral vascular disease, liver cirrhosis, coronary artery disease, diabetes mellitus, hypertension, dyslipidemia, congestive heart failure, atrial fibrillation, chronic obstructive pulmonary disease, or chronic kidney disease; and IVC filter placement during the index admission) as covariates. Covariates for the logistic regression model were determined in a stepwise fashion, with $P<.25$ required for entry into the model and $P<.15$ required to remain in the model. Treatment type was inserted without selection into a model with other significant covariates. The ICD-9-CM codes used for baseline characteristics are listed in Table E2.

Kaplan-Meier survival analysis and the log-rank test were used to compare survival after thrombolysis and surgical embolectomy. Patients with follow-up of $>5$ years were censored at 5 years, and survival estimates at 5 years were derived from the life tables. To adjust for differences in baseline characteristics, differences in survival were assessed using a Cox mode $\mathrm{l}^{11}$ incorporating all baseline characteristics as covariates. Covariates for each Cox model were determined in a stepwise fashion, with $P<.25$ required for entry into the model and $P<.15$ required to remain in the final model. Treatment type was inserted without selection into a model with other significant covariates, and hazard ratios (HRs) were reported. This analysis was also conducted to determine the effect of IVC filter placement on long-term survival. Additional analysis included only the cohort of patients who survived the index admission, with duration of survival starting from the date of discharge.

Competing-risk analysis of the secondary endpoint of recurrent PE was performed by constructing cumulative incidence curves for the 2 treatment groups and comparing them using Gray test. Patients with follow-up $>5$ years were censored at 5 years. Cox modeling and determination of HRs were done using the same methodology as for survival analysis as 


\section{The Role of Thrombolysis and Surgical Embolectomy in the Management of Acute Pulmonary Embolism}

\author{
Key findings from: \\ Lee T, Itagaki S, Chiang YP, Egorova NN, Adams DH, Chikwe J. \\ Survival and recurrence after acute pulmonary embolism treated with pulmonary \\ embolectomy or thrombolysis in New York State between 1999-2013. \\ I Thorac Cardiovasc Surg.
}

VIDEO 1. Acute pulmonary embolism: the role of thrombolysis and surgical embolectomy. Video available at: http://www.jtcvsonline.org/article/ S0022-5223(17)31765-8/fulltext.

described above. This analysis was also conducted to determine the association between IVC filter placement and cumulative incidence of recurrent PE. Additional subgroup analysis focused on events that occurred within 30 days before death or were primary diagnoses of subsequent inpatient admissions. These survival and competing-risk analyses were also repeated with patient follow-up extended from 5 to 10 years.

To adjust for potential hospital effects on outcomes, a sensitivity analysis was performed with hierarchical logistic regression and Cox proportional hazard models fit for the outcome of mortality and with clustering of patients within hospitals, controlling for all patient characteristics as above and with an additional variable controlling for admission to a center with cardiac surgery capabilities as determined by the New York State Annual Cardiac Surgery Reports (https://www.health.ny.gov/statistics/ diseases/cardiovascular/). Changes in the incidence of PE during the study period were assessed using the Cochran-Armitage test.

All tests were 2-tailed, and an $\alpha$-level of 0.05 was considered statistically significant. All statistical analyses were performed using SAS version 9.4 (SAS Institute, Cary, NC).

\section{RESULTS}

\section{Epidemiology of PE}

A total of 174,322 patients were diagnosed with acute PE in New York between 1999 and 2013, of whom 168,166 were adult residents of New York (see Table E3 for a complete CONSORT diagram). The overall incidence of PE in New York during the study period was 77.4 per 100,000 , increasing from 34.8 per 100,000 in 1999 to 105.9 per 100,000 in $2013(P<.001)$ (Figure E1). The patients with acute $P E$ had a mean age of 64.0 years (range, $18-113$ years), and $42.9 \%$ were male. Reported risk factors for PE included surgery or trauma within 30 days (30.5\%; $\mathrm{n}=51,306)$, cancer diagnosis within 2 years $(31.4 \%$; $\mathrm{n}=52,849)$, and an inherited hypercoagulable state $(2.7 \% ; \mathrm{n}=4583)$.

\section{Patient Characteristics}

A total of 4105 adult New York residents with a diagnosis of acute PE were treated with thrombolysis or surgical embolectomy in New York between 1999 and 2013. Table E4 summarizes the baseline characteristics of these patients and those who did not receive reperfusion. Of these 4105 patients, a total of 1994 patients were excluded from further analysis for one or more of the following reasons: planned admission $(n=230 ; 5.6 \%)$, pulmonary endarterectomy on the same or earlier date as the index procedure $(\mathrm{n}=13 ; 0.3 \%)$, IVC filter placement before the index admission $(\mathrm{n}=145 ; 3.5 \%)$, PE not the primary diagnosis for admission $(\mathrm{n}=1712 ; 42.7 \%)$, and reperfusion within 3 days after admission $(\mathrm{n}=177 ; 4.3 \%)$. After applying all exclusion criteria, 2111 patients remained, of whom $1854(87.8 \%)$ underwent thrombolysis and $257(12.2 \%)$ underwent surgical embolectomy. The median duration of follow-up was 4.2 years (range, $0-16.3$ years) in the thrombolysis group and 4.3 years (range, $0-16.0$ years) in the surgery group.

The patients in the thrombolysis and surgery groups were of similar age $(58.5 \pm 16.7$ years vs $58.7 \pm 16.1$ years; $P=.85)$, but the thrombolysis group had a lower proportion of males $(43 \%$ vs $57 \% ; P<.001)$ (Table 1). The thrombolysis group also had fewer patients with a history of or presentation with ileofemoral deep vein thrombosis $(24 \%$ vs $31 \% ; P<.001)$, PE $(13 \%$ vs $28 \%$; $P<.001)$, major surgery or trauma within 30 days $(8 \%$ vs $18 \% ; P<.001)$, or congestive heart failure $(19 \%$ vs $31 \% ; P<.001)$. The patients in the thrombolysis patients were less likely to have contraindications to thrombolysis of ischemic stroke within the last 6 months (1\% vs $3 \%$; $P=.015)$, known coagulopathies ( $8 \%$ vs $14 \%$; $P<.001)$, or a history of cerebrovascular disease $(4 \%$ vs $9 \% ; P<.001)$. IVC filters were placed less frequently with thrombolysis than with surgical embolectomy $(32 \%$ vs $83 \% ; P<.001)$.

\section{0-Day Outcomes}

There was no difference in 30-day mortality between the thrombolysis and surgical embolectomy groups $(15.2 \%$ vs $13.2 \%$; odds ratio [OR], $1.12 ; 95 \%$ confidence interval [CI], 0.72-1.73) (Table 2). Thrombolysis was associated with a greater risk of reintervention $(3.8 \%$ vs $1.2 \%$; OR, 7.16; 95\% CI, 2.17-23.62), but with a lower risk of major bleeding (3.6\% vs $9.0 \%$; OR, 0.53; 95\% CI, 0.31-0.92) compared with surgery. There was no significant betweengroup difference in rates of recurrent $\mathrm{PE}$ within 30 days (7.4\% vs $8.6 \%$; OR, 0.99 ; 95\% CI, 0.61-1.61), recurrent deep vein thrombosis $(4.9 \%$ vs $4.7 \%$; OR, $1.03 ; 95 \% \mathrm{CI}$, $0.53-1.99)$, and requirement for blood transfusion (12.1\% vs $19.8 \%$; OR, 0.73 ; $95 \%$ CI, 0.49-1.07). Thrombolysis was associated with a greater risk of stroke $(1.9 \%$ vs $0.8 \%$; OR, 4.70; 95\% CI, 1.08-20.42).

Hemodynamic instability (defined as presentation with cardiac arrest, shock, systemic hypotension, syncope, respiratory failure, or the need for mechanical ventilation before reperfusion treatment) was present in $40.1 \%$ of the thrombolysis group and $44.8 \%$ of the surgical group $(P=.15)$. Instability was associated with higher 30-day 
TABLE 1. Baseline patient characteristics in the overall cohort and according to type of treatment

\begin{tabular}{|c|c|c|c|c|c|}
\hline Characteristic & $\begin{array}{c}\text { All patients } \\
(\mathbf{n}=\mathbf{2 1 1 1})\end{array}$ & $\begin{array}{l}\text { Thrombolysis } \\
(\mathbf{n}=\mathbf{1 8 5 4})\end{array}$ & $\begin{array}{l}\text { Surgery } \\
(\mathbf{n}=\mathbf{2 5 7})\end{array}$ & $P$ value & Std diff, $\%$ \\
\hline \multicolumn{6}{|l|}{ Demographic data } \\
\hline Age, mean $\pm S D$, years & $58.5 \pm 16.7$ & $58.5 \pm 16.7$ & $58.7 \pm 16.1$ & .85 & 1.3 \\
\hline Male sex, $\mathrm{n}(\%)$ & $950(45)$ & $803(43)$ & $147(57)$ & $<.001$ & 28.1 \\
\hline Race, $\mathrm{n}(\%)$ & & & & .002 & \\
\hline White & $1309(62)$ & $134(52)$ & $1175(64)$ & & -22.9 \\
\hline Black & $430(20)$ & $67(26)$ & $363(22)$ & & 15.5 \\
\hline Hispanic & $98(5)$ & $10(4)$ & $88(5)$ & & -4.2 \\
\hline Other/unknown & $274(13)$ & $46(18)$ & $228(12)$ & & 15.7 \\
\hline \multicolumn{6}{|c|}{ Risk factors for pulmonary embolism, $\mathrm{n}(\%)$} \\
\hline Past or present deep vein thrombosis & $954(45)$ & $828(45)$ & $126(49)$ & .19 & 8.8 \\
\hline Ileofemoral vein thrombosis & $518(25)$ & $438(24)$ & $80(31)$ & $<.001$ & 16.9 \\
\hline History of pulmonary embolism & $313(15)$ & $240(13)$ & $73(28)$ & $<.001$ & 38.9 \\
\hline Cancer & $374(18)$ & $326(18)$ & $48(19)$ & .67 & 2.8 \\
\hline Major surgery or trauma $<30 \mathrm{~d}$ & $186(9)$ & $140(8)$ & $46(18)$ & $<.001$ & 31.4 \\
\hline Major orthopedic surgery & $52(2)$ & $41(2)$ & $11(4)$ & .045 & 11.7 \\
\hline Major nonorthopedic surgery & $117(6)$ & $82(4)$ & $35(14)$ & $<.001$ & 32.5 \\
\hline Major trauma & $46(2)$ & $37(2)$ & $9(4)$ & .12 & 9.2 \\
\hline Hypercoagulable state & $104(5)$ & $85(5)$ & $19(7)$ & .051 & 11.9 \\
\hline \multicolumn{6}{|l|}{ Contraindications for thrombolysis, $\mathrm{n}(\%)$} \\
\hline Major bleeding, $<30 \mathrm{~d}$ & $129(6)$ & $108(6)$ & $21(8)$ & .14 & 9.2 \\
\hline Ischemic stroke, $<6$ mo & $28(1)$ & $20(1)$ & $8(3)$ & .015 & 14.2 \\
\hline Coagulopathy & $176(8)$ & $140(8)$ & $36(14)$ & $<.001$ & 20.9 \\
\hline Cerebrovascular disease & $106(5)$ & $82(4)$ & $24(9)$ & $<.001$ & 19.5 \\
\hline Peripheral vascular disease & $37(2)$ & $32(2)$ & $5(2)$ & .80 & 16.4 \\
\hline Liver cirrhosis & $12(1)$ & $11(1)$ & $1(0)$ & .68 & -2.9 \\
\hline \multicolumn{6}{|l|}{ Comorbidities, $\mathrm{n}(\%)^{*}$} \\
\hline Coronary artery disease & $377(18)$ & $320(17)$ & $57(22)$ & .054 & 12.4 \\
\hline Diabetes mellitus & $453(21)$ & 407 (22) & $46(18)$ & .14 & -10.2 \\
\hline Hypertension & $1158(55)$ & $1020(55)$ & $138(54)$ & .69 & -2.7 \\
\hline Dyslipidemia & $616(29)$ & $535(29)$ & $81(32)$ & .38 & 5.8 \\
\hline Congestive heart failure & $429(20)$ & $350(19)$ & $79(31)$ & $<.001$ & 27.7 \\
\hline Atrial fibrillation & $209(10)$ & $181(10)$ & $28(11)$ & .57 & 3.7 \\
\hline Chronic obstructive airway disease & $412(20)$ & $363(20)$ & $49(19)$ & .85 & -1.3 \\
\hline Chronic kidney disease & $167(8)$ & $148(8)$ & $19(7)$ & .74 & -2.2 \\
\hline IVC filter during admission & $799(38)$ & $585(32)$ & $214(83)$ & $<.001$ & 122.7 \\
\hline \multicolumn{6}{|l|}{ Year of treatment, $\mathrm{n}(\%)$} \\
\hline 1999 & $53(3)$ & $52(3)$ & $1(0)$ & & \\
\hline 2000 & $82(4)$ & $75(4)$ & $7(3)$ & & \\
\hline 2001 & $80(4)$ & $72(4)$ & $8(3)$ & & \\
\hline 2002 & $73(3)$ & $65(4)$ & $8(3)$ & & \\
\hline 2003 & $96(5)$ & $92(5)$ & $4(2)$ & & \\
\hline 2004 & $91(4)$ & $82(4)$ & $9(4)$ & & \\
\hline 2005 & $126(6)$ & $119(6)$ & $7(3)$ & & \\
\hline 2006 & $131(6)$ & $112(6)$ & $19(7)$ & & \\
\hline 2007 & $113(5)$ & $93(5)$ & $20(8)$ & & \\
\hline 2008 & $150(7)$ & $125(7)$ & $25(10)$ & & \\
\hline 2009 & $201(10)$ & $162(9)$ & $39(15)$ & & \\
\hline 2010 & $185(9)$ & $161(9)$ & $24(9)$ & & \\
\hline 2011 & 224 (11) & 195 (11) & $29(11)$ & & \\
\hline 2012 & $215(10)$ & 184 (10) & $31(12)$ & & \\
\hline 2013 & 291 (14) & 265 (14) & $26(10)$ & & \\
\hline
\end{tabular}

Std diff, Standardized difference; $S D$, standard deviation; $I V C$, inferior vena cava. *Comorbidities were diagnosed at index admission or within 2 years of index admission, unless specified otherwise. 
TABLE 2. Outcomes within 30 days of treatment with thrombolysis or surgical embolectomy

\begin{tabular}{|c|c|c|c|c|}
\hline Outcome & $\begin{array}{c}\text { Thrombolysis } \\
(\mathbf{n}=\mathbf{1 8 5 4}), \mathbf{n}(\%)\end{array}$ & $\begin{array}{c}\text { Surgery } \\
(\mathbf{n}=\mathbf{2 5 7}), \mathbf{n}(\%)\end{array}$ & OR $(95 \% \text { CI })^{*}$ & $P$ value \\
\hline Mortality & $282(15.2)$ & $34(13.2)$ & $1.12(0.72-1.73)$ & .62 \\
\hline Recurrent pulmonary embolism & $137(7.4)$ & $22(8.6)$ & $0.99(0.61-1.61)$ & .97 \\
\hline Recurrent pulmonary embolism necessitating inpatient readmission & $46(2.5)$ & $3(1.2)$ & $1.20(0.81-1.76)$ & .37 \\
\hline Recurrent deep vein thrombosis & $73(4.9)$ & $12(4.7)$ & $1.03(0.53-1.99)$ & .93 \\
\hline Reoperation or reintervention $\dagger$ & $71(3.8)$ & $3(1.2)$ & $7.16(2.17-23.62)$ & .001 \\
\hline Stroke & $35(1.9)$ & $2(0.8)$ & $4.70(1.08-20.42)$ & .039 \\
\hline Major bleed & $67(3.6)$ & $23(9.0)$ & $0.53(0.31-0.92)$ & .024 \\
\hline Blood transfusion & $225(12.1)$ & $51(19.8)$ & $0.73(0.49-1.07)$ & .11 \\
\hline
\end{tabular}

$O R$, Odds ratio; $C I$, confidence interval. *Adjusted using logistic regression analysis, with all patient demographics and baseline characteristics entered as covariates into initial model, and covariates in the final model determined via stepwise selection with $P=.25$ for entry into the model and $P=.15$ to stay in the model. $\dagger$ Reoperation or reintervention included surgical embolectomy, thrombolysis, and pulmonary endareterectomy.

mortality $(29.5 \%$ vs $5.0 \%$; OR, 8.03 ; $95 \%$ CI, $5.93-$ 10.87). There was no between-group difference in 30day mortality in the subgroups of patients with hemodynamic instability.

Reperfusion was administered at 165 centers; all centers administered thrombolysis, and $55(33 \%)$ also performed surgical embolectomy. There was no significant difference in outcomes when hospital was incorporated as a random effect, or when a dichotomous variable for treatment at centers with cardiac surgery capability was added (Table E5). In other words, initial admission to a hospital with cardiac surgery capability was not associated with improved survival compared with initial admission to a hospital without cardiac surgery.

\section{Long-Term Outcomes}

There was no difference in long-term survival between the thrombolysis and surgical embolectomy groups when analyzed from the date of intervention (Figure 1), or when analyzed in patients who survived the index hospitalization. Actuarial 5-year survival was $72.4 \%(95 \%$ CI, $70.3 \%$ $74.5 \%)$ in the thrombolysis group and $76.1 \%(95 \% \mathrm{CI}$, $70.2 \%-81.0 \%)$ in the surgical group. The HR for death was 1.11 (95\% CI, 0.83-1.49). Outcomes at 10 years are presented in Figure E2. Actuarial 5-year survival from the time of discharge was $84.7 \%(95 \% \mathrm{CI}, 82.7 \%-86.5 \%)$ in the thrombolysis group and $87.8 \%(95 \% \mathrm{CI}, 82.3 \%$ $91.6 \%$ ) in the surgical group. In the multivariable analysis, after controlling for baseline comorbidities and year of procedures, the HR for mortality for thrombolysis versus surgery was 1.44 (95\% CI, 0.93-2.24).

There was no difference in the cumulative incidence of recurrent $\mathrm{PE}$ following thrombolysis and surgery (Figure 2, A). The 5-year cumulative incidence of PE was $18.8 \%$ (95\% CI, $16.9 \%-20.8 \%)$ in the thrombolysis group and $20.0 \%$ (95\% CI, $15.0 \%-25.8 \%)$ in the surgical group. The HR for recurrent PE was 0.88 (95\% CI, 0.64-1.21).
However, the thrombolysis group had a higher rate of recurrent $\mathrm{PE}$ requiring inpatient readmission (Figure 2, B); the 5year cumulative incidence of such events was $7.9 \%(95 \%$ CI, $6.9 \%-9.4 \%$ ) in the thrombolysis group and $2.8 \%$ ( $95 \% \mathrm{CI}, 1.1 \%-5.8 \%)$ in the surgical group, and the HR for such events was 3.38 (95\% CI, 1.48-7.73). Outcomes at 10 years are presented in Figure E3. The rate of recurrent PE within 30 days before death was in $1.3 \%(\mathrm{n}=25)$ in the thrombolysis group and $0.3 \%(\mathrm{n}=1)$ in the surgical group. A total of 35 patients who received initial thrombolysis underwent subsequent surgery; no patients received initial surgery and then required subsequent thrombolysis.

In an analysis limited to patients who survived their index hospitalization, IVC filters were associated with worse survival (Figure E4, B), but had no significant effect on the incidence of recurrent PE (Table E6). The actuarial 5-year survival from the date of discharge was $78.4 \%(95 \% \mathrm{CI}$,

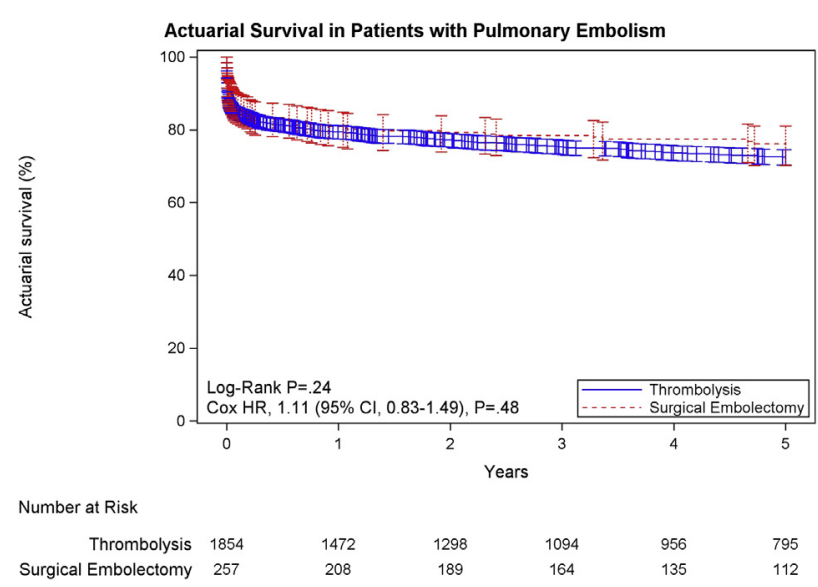

FIGURE 1. Actuarial survival following treatment of acute pulmonary embolism with thrombolysis versus surgical embolectomy in New York State from 1999 to 2013, among all patients, from the date of procedure. $H R$, Hazard ratio; $C I$, confidence interval. 

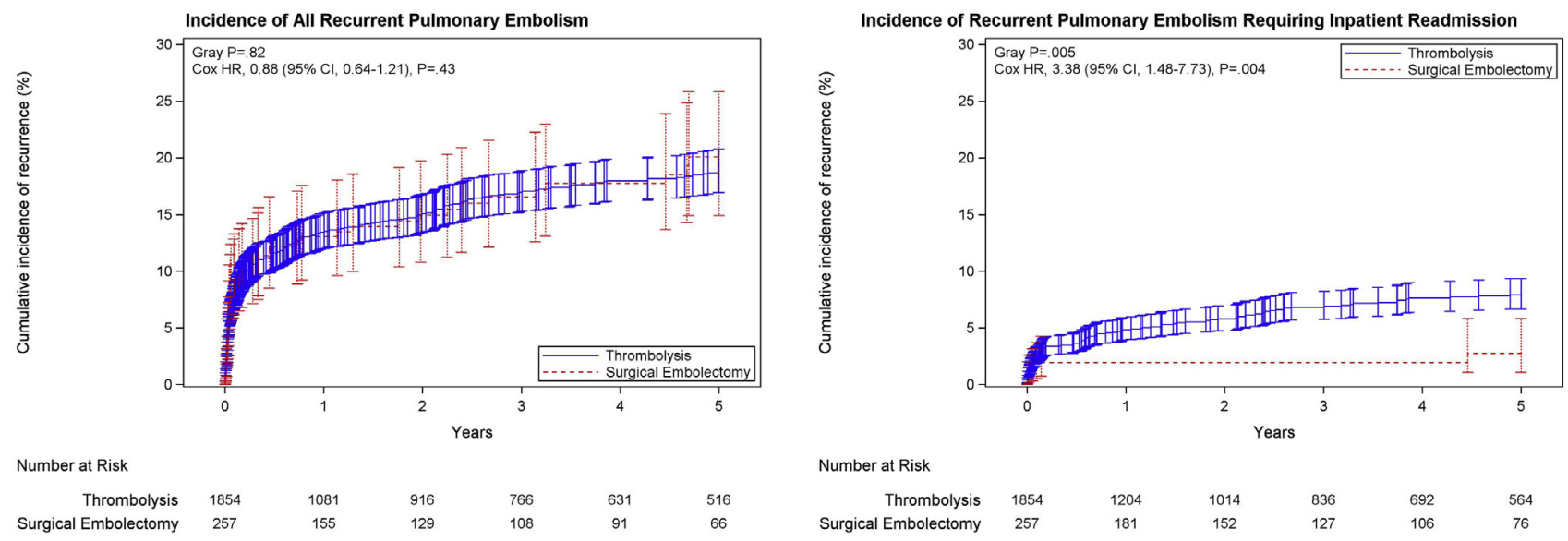

A

B

FIGURE 2. Cumulative incidence of recurrent pulmonary embolism following thrombolysis versus surgical embolectomy among all patients. A, All recurrent pulmonary embolic events. B, Recurrent pulmonary embolism necessitating inpatient readmission. HR, Hazard ratio; $C I$, confidence interval.

$74.5 \%-81.8 \%)$ in the filter group and $84.1 \%(95 \% \mathrm{CI}$, $81.3 \%-86.5 \%)$ in the nonfilter group. The HR for death was $1.38(95 \% \mathrm{CI}, 1.05-1.80)$. Additional predictors of long-term mortality and recurrent PE are listed in Tables E6 and E7, respectively.

\section{DISCUSSION}

Current consensus guidelines for the treatment of highrisk PE have been formulated in the absence of robust outcome data for surgical embolectomy, and the choice of therapeutic strategy remains an area of uncertainty. ${ }^{4,5,12}$ Our study suggests that with appropriate selection of surgical candidates, surgical embolectomy offers similar early and long-term survival as thrombolysis. This finding supports current recommendations for surgical pulmonary embolectomy to treat patients with intermediate and highrisk PE in whom thrombolysis is contraindicated or has failed. ${ }^{4,5}$ Importantly, we found that surgical embolectomy appears to have a very good safety profile, with lower associated risks of early stroke, reintervention, and late recurrent PE compared with thrombolysis.

Our present findings confirm data from 3 single-center studies reporting comparable survival benefit with thrombolysis and surgical embolectomy. ${ }^{6-8}$ Aymard and colleagues ${ }^{6}$ analyzed 80 patients with hemodynamic instability or right ventricular dysfunction and found no significant differences between thrombolysis and surgery groups in terms of in-hospital mortality $(14 \%$ vs $4 \% ; P=.25)$ and long-term mortality $(23 \%$ vs $18 \% ; P=.60)$ at a mean follow-up of 5 years. Another analysis of 27 patients reported an in-hospital mortality rate of $33 \%$ with thrombolysis and $23 \%$ with surgical embolectomy, ${ }^{7}$ and a study of 40 patients with acute PE who initially underwent thrombolysis but did not improve clinically found an in-hospital mortality of $38 \%$ with repeat thrombolysis but only $7 \%$ with rescue embolectomy $(P=.07) .{ }^{8}$ The foregoing studies were underpowered to detect significant differences in mortality, however, which led us to explore outcomes in a much larger patient population. The absence of a significant difference in mortality between the 2 treatment strategies in this multicenter cohort puts greater emphasis on major morbidities, including recurrent PE.

In our analysis, the overall rate of recurrent PE did not differ between the 2 treatment groups; however, recurrent PE necessitating hospital admission was significantly more frequent in the thrombolysis group. In addition, patients who underwent thrombolysis as index treatment were significantly more likely to require repeat reperfusion therapy. This higher incidence of significant recurrent PE after thrombolysis compared with after surgical embolectomy may be related to the fact that thrombolysis reduces the thrombus burden more slowly and less completely than surgical embolectomy, particularly in patients with right heart thrombi. ${ }^{13}$ The presence of residual thrombus is associated with an elevated risk of chronic thromboembolic pulmonary hypertension, with a reported incidence of $0.1 \%$ to $9.1 \%$ within 2 years of a symptomatic PE. ${ }^{14}$ In our analysis, the differences in recurrent PE were independent of the use of IVC filters, the benefits of which remain controversial, with wide variation in reported use. ${ }^{15-17}$

We observed an increased risk of stroke within 30 days of thrombolysis compared with surgical embolectomy. The reported frequency of intracranial hemorrhage is $1.5 \%$ to $2.0 \%$ after thrombolysis for PE. ${ }^{3,18,19}$ Absolute contraindications to thrombolysis include previous history of hemorrhagic stroke; any history of stroke, dementia, or central nervous system damage within 12 months; head trauma or brain surgery within 6 months; and known intracranial neoplasm. ${ }^{4,50}$ Approximately $7 \%$ of patients evaluated for thrombolysis in a multicenter study performed in New Zealand were reported to have 1 or more contraindications. ${ }^{21}$ These data appear to support 
the use of surgical reperfusion in patients with acute $\mathrm{PE}$ and relative contraindications for thrombolysis.

\section{Study Strengths and Limitations}

To the best of our knowledge, this study represents the largest comparison of long-term outcomes after surgical embolectomy versus thrombolysis reported to date. The strengths of this mandatory administrative dataset include the comprehensive longitudinal follow-up of patients, allowing an evaluation of long-term outcomes not supported by existing clinical registries. However, administrative datasets have major limitations as a source of clinical outcomes data, including the lack of information used to determine treatment strategies, such as clinical and hemodynamic variables; the size and location of thrombi; the presence of right heart dysfunction, including strain; and anticoagulation therapy after hospital discharge. This significantly limited our ability to accurately stratify patients into sub-massive and massive PE groups, and to fully account for important confounding variables affecting long-term recurrence and survival after pulmonary embolectomy. We attribute the increase in the incidence of PE primarily to the increased use of spiral computed tomography scans. ${ }^{22}$ Despite the relatively large number of patients in this study, it remained underpowered for the $10 \%$ relative reduction in 30 -day mortality with embolectomy compared with thrombolysis needed to reach statistical significance. The lack of information on outpatient anticoagulation is a particular barrier to evaluating the outcomes of patients according to whether or not they underwent placement of an IVC filter, given that a significant number of patients receive filters because they cannot comply with anticoagulation. These patients may have been sicker at baseline than patients who did not receive a filter, potentially explaining the worse survival that we observed.

\section{CONCLUSIONS}

Surgical embolectomy offers similar early and late survival as thrombolysis, with superior freedom from recurrent PE, early stroke, and reintervention. These data support current consensus guidelines recommending surgical pulmonary embolectomy for the treatment of patients with PE in whom thrombolysis is contraindicated or has failed. In addition, the safety and efficacy profile of surgical embolectomy in this retrospective analysis suggest that a prospective trial may help determine the most effective treatment strategy for patients with PE who are candidates for both thrombolysis and surgical reperfusion.

\section{Conflict of Interest Statement}

Authors have nothing to disclose with regard to commercial support.

\section{References}

1. Mozaffarian D, Benjamin EJ, Go AS, Arnett DK, Blaha MJ, Cushman M, et al. Heart disease and stroke statistics-2016 update: a report from the American Heart Association. Circulation. 2016;133:e38-360.

2. Roger VL, Go AS, Lloyd-Jones DM, Adams RJ, Berry JD, Brown TM, et al. Heart disease and stroke statistics-2011 update: a report from the American Heart Association. Circulation. 2016;123:e18-209.

3. Chatterjee S, Chakraborty A, Weinberg I, Kadakia M, Wilensky RL, Sardar P, et al. Thrombolysis for pulmonary embolism and risk of all-cause mortality, major bleeding, and intracranial hemorrhage: a meta-analysis. JAMA. 2014;311:2414-21.

4. Jaff MR, McMurtry MS, Archer SL, Cushman M, Goldenberg N, Goldhaber SZ, et al. Management of massive and submassive pulmonary embolism, iliofemoral deep vein thrombosis, and chronic thromboembolic pulmonary hypertension: a scientific statement from the American Heart Association. Circulation. 2011;123:1788-830.

5. Konstantinides SV, Torbicki A, Agnelli G, Danchin N, Fitzmaurice D, Galiè N, et al. 2014 ESC guidelines on the diagnosis and management of acute pulmonary embolism. Eur Heart J. 2014;35:3033-69.

6. Aymard T, Kadner A, Widmer A, Basciani R, Tevaearai H, Weber A, et al. Massive pulmonary embolism: surgical embolectomy versus thrombolytic therapy—should surgical indications be revisited? Eur J Cardiothorac Surg. 2013; 43:90-4; discussion 94.

7. Gulba DC, Schmid C, Borst HG, Lichtlen P, Dietz R, Luft FC. Medical compared with surgical treatment for massive pulmonary embolism. Lancet. 1994;343:576-7.

8. Meneveau N, Séronde MF, Blonde MC, Legalery P, Didier-Petit K, Briand F, et al. Management of unsuccessful thrombolysis in acute massive pulmonary embolism. Chest. 2006;129:1043-50.

9. Greelish JP, Leacche M, Solenkova NS, Ahmad RM, Byrne JG. Improved midterm outcomes for type A (central) pulmonary emboli treated surgically. $J$ Thorac Cardiovasc Surg. 2011;142:1423-9.

10. Centers for Disease Control and Prevention. Bridged-race population estimates 1990-2014. Available at: http://wonder.cdc.gov/Bridged-Race-v2014.html. Accessed December 29, 2016.

11. Cox DR. Regression models and life-tables. J R Stat Soc Series B Stat Methodol. $1972 ; 34: 187-220$

12. Condliffe R, Elliot CA, Hughes RJ, Hurdman J, Maclean RM, Sabroe I, et al. Management dilemmas in acute pulmonary embolism. Thorax. 2014;69:174-80.

13. Ferrari E, Benhamou M, Berthier F, Baudouy M. Mobile thrombi of the right heart in pulmonary embolism: delayed disappearance after thrombolytic treatment. Chest. 2005;127:1051-3.

14. Lang IM, Pesavento R, Bonderman D, Yuan JX. Risk factors and basic mechanisms of chronic thromboembolic pulmonary hypertension: a current understanding. Eur Respir J. 2013;41:462-8.

15. Bikdeli B, Wang Y, Minges KE, Desai NR, Kim N, Desai MM, et al. Vena caval filter utilization and outcomes in pulmonary embolism: Medicare hospitalizations from 1999 to 2010. J Am Coll Cardiol. 2016;67:1027-35.

16. Goldhaber SZ, Visani L, De Rosa M. Acute pulmonary embolism: clinical outcomes in the International Cooperative Pulmonary Embolism Registry (ICOPER). Lancet. 1999;353:1386-9.

17. White RH, Brunson A, Romano PS, Li Z, Wun T. Outcomes after vena cava filter use in noncancer patients with acute venous thromboembolism. Circulation. 2016;133:2018-29.

18. Kanter DS, Mikkola KM, Patel SR, Parker JA, Goldhaber SZ. Thrombolytic therapy for pulmonary embolism. Frequency of intracranial hemorrhage and associated risk factors. Chest. 1997;111:1241-5.

19. Meyer G, Vicaut E, Danays T, Agnelli G, Becattini C, Beyer-Westendorf J, et al. Fibrinolysis for patients with intermediate-risk pulmonary embolism. $N$ Engl J Med. 2014;370:1402-11.

20. O'Gara PT, Kushner FG, Ascheim DD, Casey DE Jr, Chung MK, de Lemos JA, et al. 2013 ACCF/AHA guideline for the management of ST-elevation myocardial infarction: executive summary: a report of the American College of Cardiology Foundation/American Heart Association Task Force on Practice Guidelines. J Am Coll Cardiol. 2013;61:485-510.

21. French JK, Williams BF, Hart HH, Wyatt S, Poole JE, Ingram C, et al. Prospective evaluation of eligibility for thrombolytic therapy in acute myocardial infarction. BMJ. 1996;312:1637-41.

22. Wiener RS, Schwartz LM, Woloshin S. Time trends in pulmonary embolism in the United States: evidence of overdiagnosis. Arch Intern Med. 2011;171:831-7.

Key Words: pulmonary embolism, venous thromboembolism, deep vein thrombosis, pulmonary embolectomy, thrombolysis 


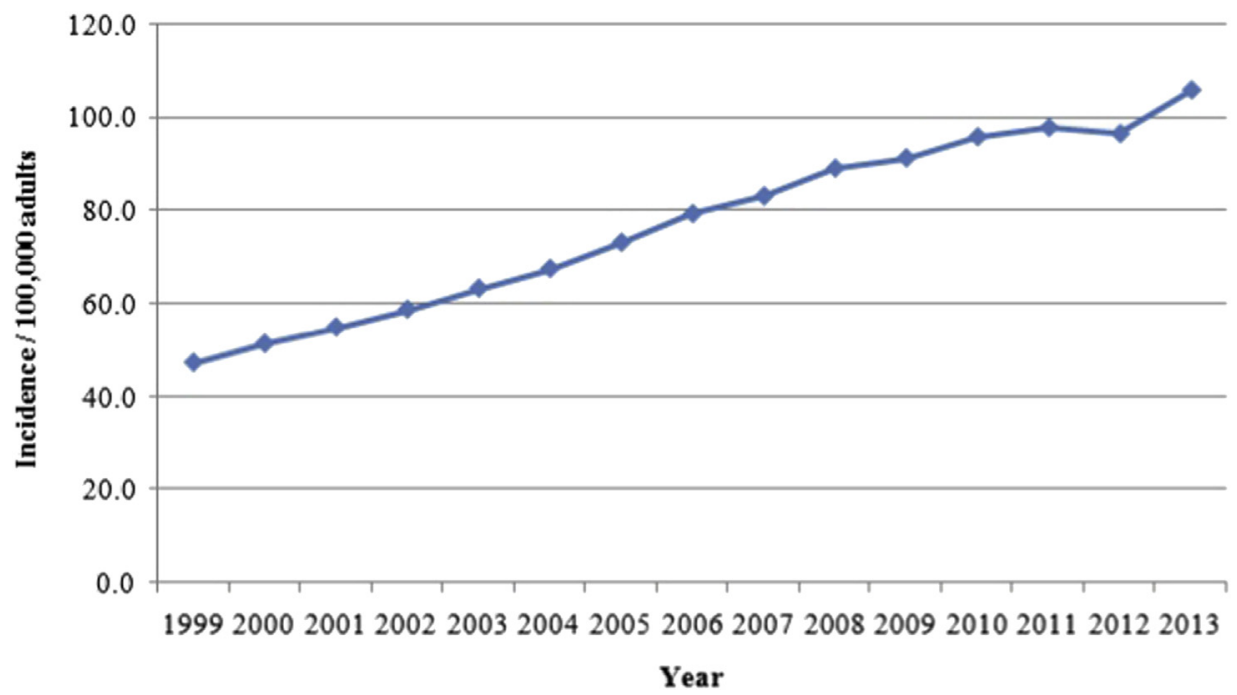

FIGURE E1. Incidence of acute pulmonary embolism in New York State, 1999 to 2013. Cochran-Armitage test for trend, $P<.001$.

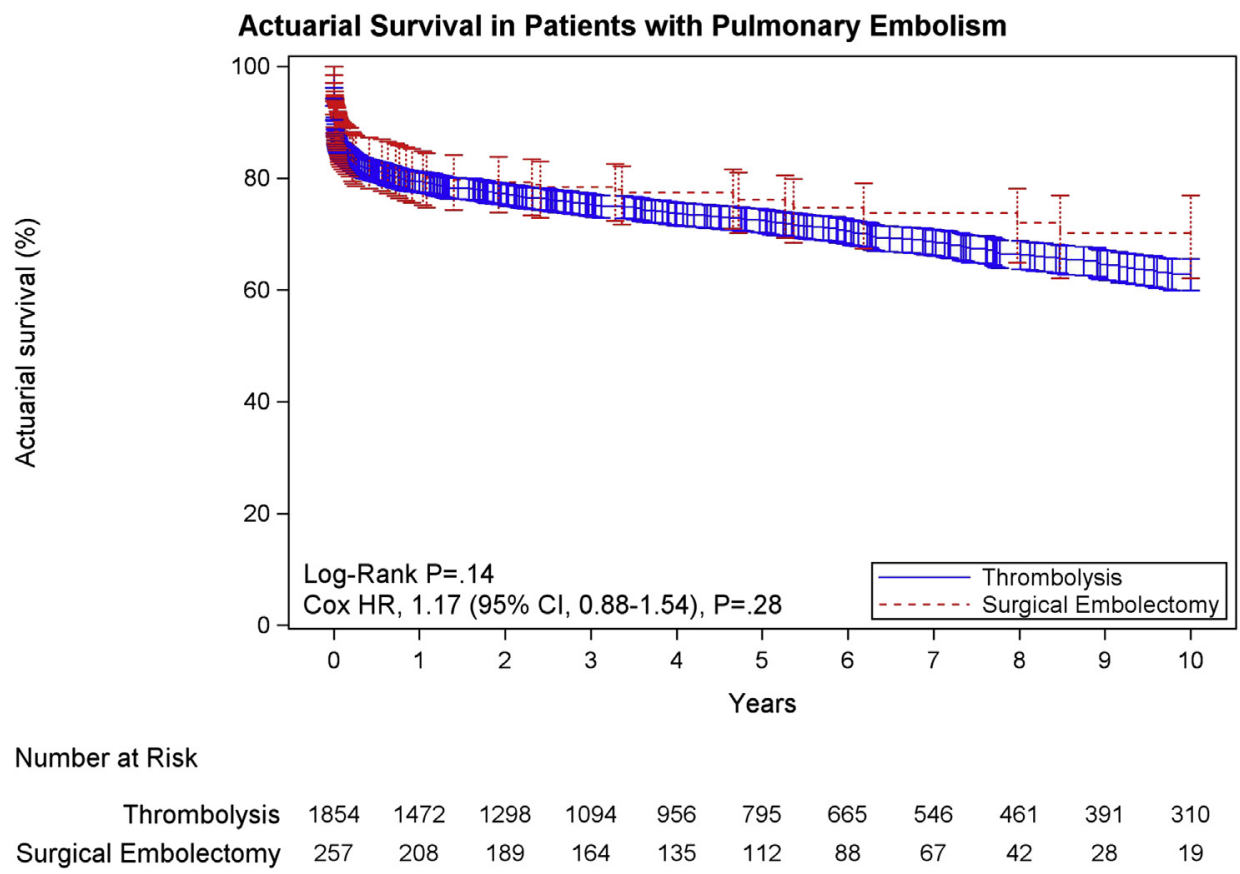

FIGURE E2. Actuarial 10-year survival following treatment of acute pulmonary embolism with thrombolysis versus surgical embolectomy in New York State, 1999 to 2013, among all patients, from the date of the procedure. $H R$, Hazard ratio; $C I$, confidence interval. 


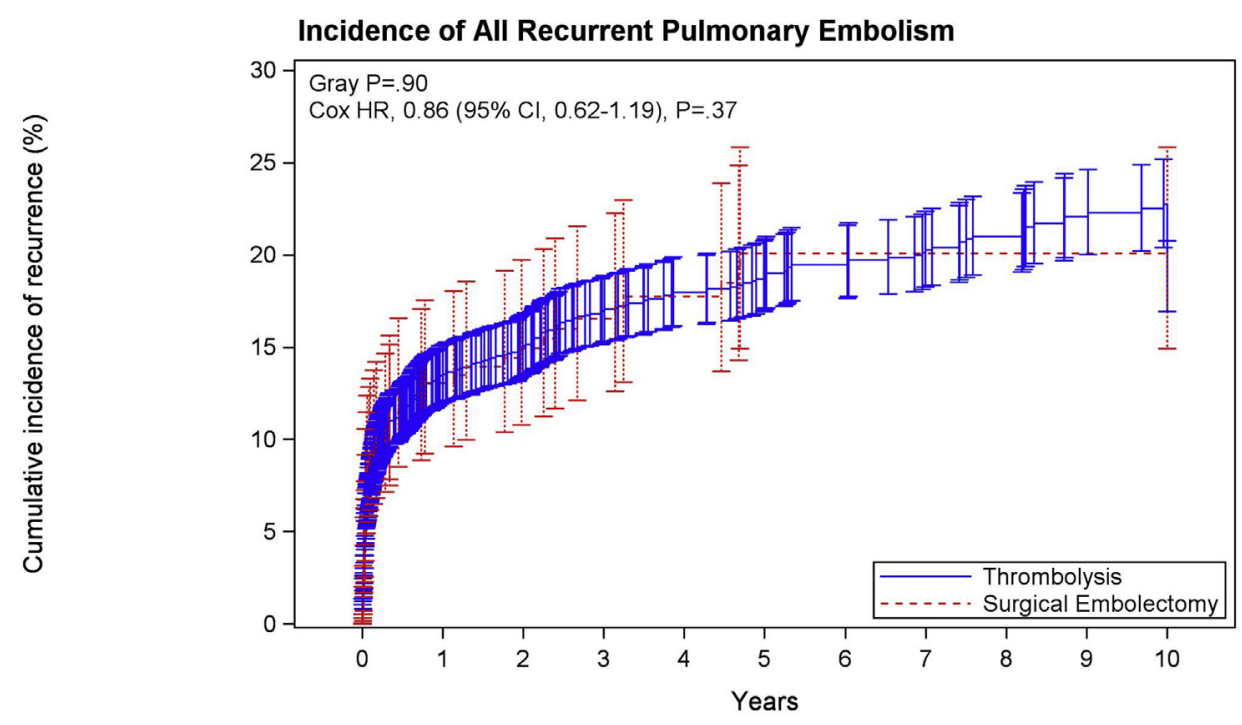

Number at Risk

$\begin{array}{rccccccccccc}\text { Thrombolysis } & 1854 & 1081 & 916 & 766 & 631 & 516 & 431 & 367 & 301 & 229 & 180 \\ \text { Surgical Embolectomy } & 257 & 155 & 129 & 108 & 91 & 66 & 48 & 38 & 24 & 18 & 11\end{array}$

A

Incidence of Recurrent Pulmonary Embolism Requiring Inpatient Readmission

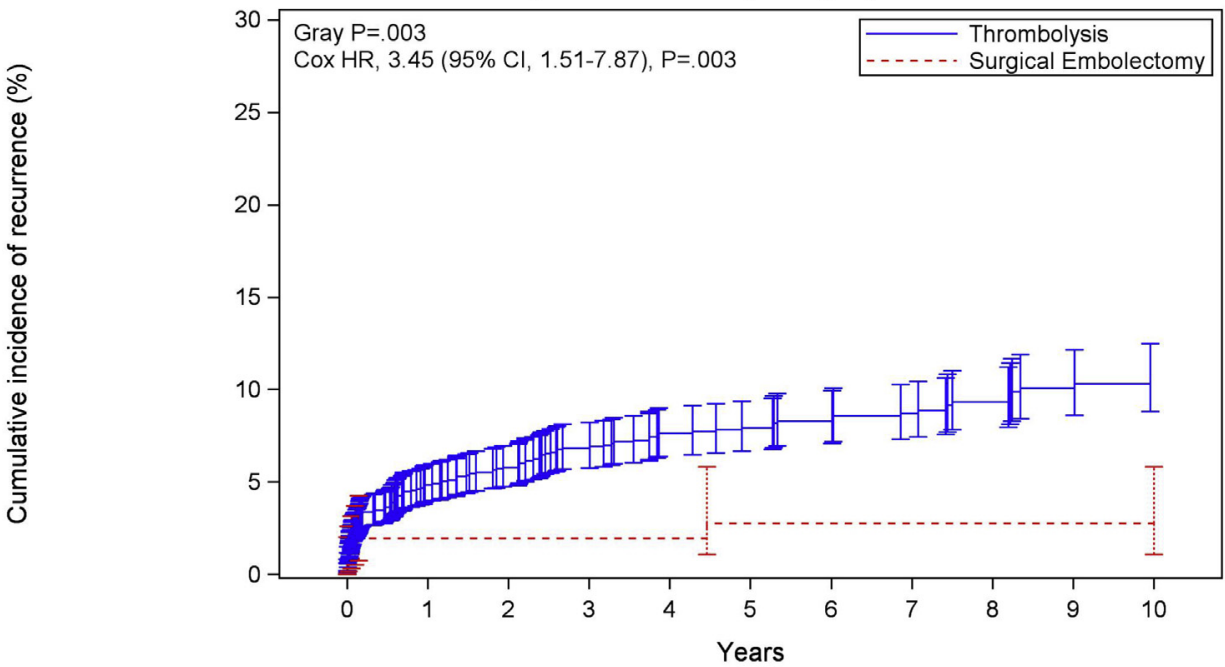

Number at Risk

$\begin{array}{llllllllllll}\text { Thrombolysis } & 1854 & 1204 & 1014 & 836 & 692 & 564 & 472 & 404 & 329 & 249 & 194\end{array}$

$\begin{array}{llllllllllll}\text { Surgical Embolectomy } & 257 & 181 & 152 & 127 & 106 & 76 & 53 & 39 & 24 & 18 & 11\end{array}$

\section{B}

FIGURE E3. Cumulative 10-year incidence of recurrent pulmonary embolism following thrombolysis versus surgical embolectomy among all patients. A, All recurrent pulmonary embolic events. B, Recurrent pulmonary embolism necessitating inpatient readmission. $H R$, Hazard ratio; $C I$, confidence interval. 


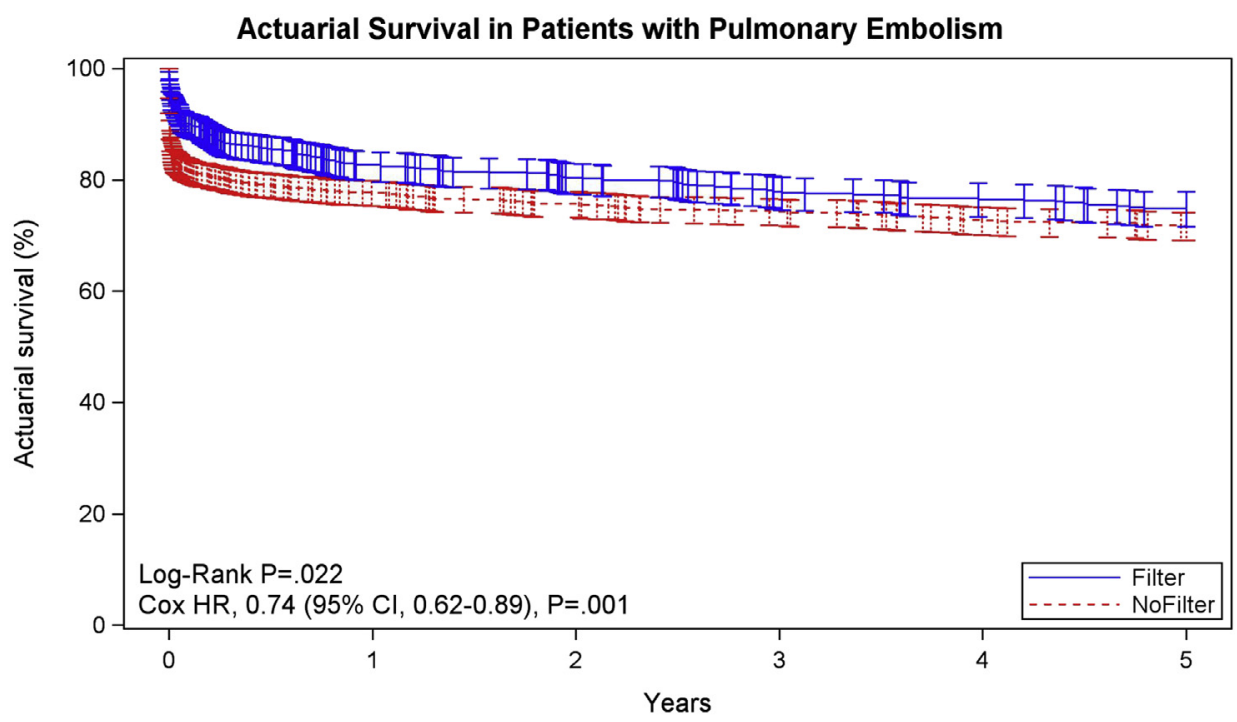

Number at Risk

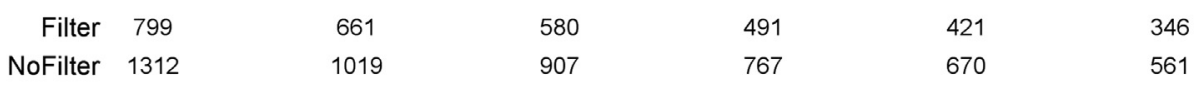

A

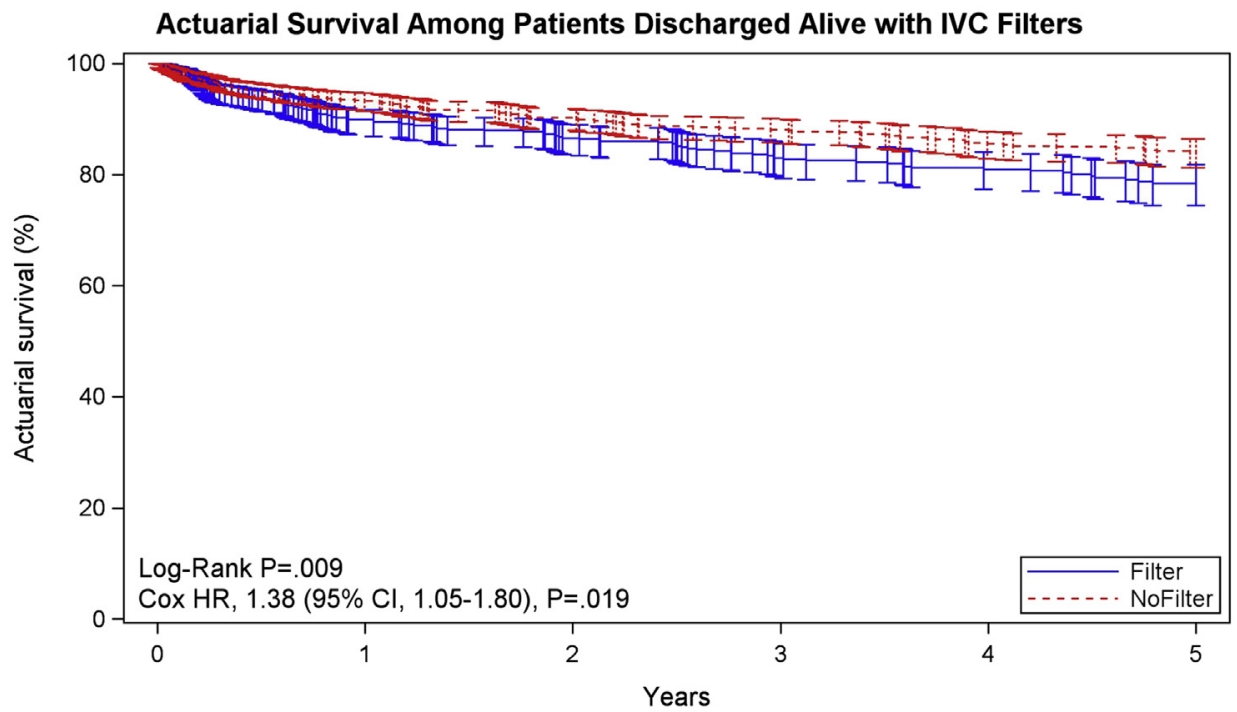

Number at Risk

$\begin{array}{rlllll}\text { Filter } 662 & 526 & 446 & 362 & 291 & 227 \\ \text { NoFilter } 996 & 808 & 702 & 585 & 502 & 426\end{array}$

\section{B}

FIGURE E4. Actuarial survival following treatment of acute pulmonary embolism according to inferior vena cava filter placement during the index admission versus no filter. A, Among all patients, from the date of the procedure. B, Among patients discharged alive, from the date of discharge. $H R$, Hazard ratio; $C I$, confidence interval; $I V C$, inferior vena cava. 
TABLE E1. Definitions of study endpoints

\begin{tabular}{|c|c|}
\hline Endpoint & International Classification of Diseases, Ninth Revision, Clinical Modification (ICD-9-CM) diagnosis codes \\
\hline Pulmonary embolism & From index or subsequent admissions: 4151, 41511, 41512, 41513, and 41519 \\
\hline Deep vein thrombosis & $\begin{array}{l}\text { From subsequent admissions: 4511, 45111, 45118, 45119, 4512, 45181, 45183, 45184, 45189, 4519, 452, 4530, 4531, } \\
\quad 4532,4533,4534,45340,45341,45342,4538,4539,6713,67130,67131,67133,6714,67140,67141,67142,67144, \\
6715,67150,67151,67152,67153,67154 \text {, and } 6719\end{array}$ \\
\hline Stroke & $\begin{array}{l}\text { From index or subsequent admissions: } \\
\text { Hemorrhagic stroke: } 430,431,432,4320,4321,4329 \text {, and } 99702 \\
\text { Ischemic stroke: } 43301,43311,43321,43331,43381,43391,43401,43411,43491,436,4370 \text {, and } 4371\end{array}$ \\
\hline Major bleeding & $\begin{array}{l}\text { From index or subsequent admissions: } \\
\text { Tamponade/hemopericardium: } 4230 \text { and } 4233 \\
\text { Gastrointestinal hemorrhage: } 4560,45620,53021,53082,5310,53100,53101,5312,53120,53121,5320,53200,53201 \text {, } \\
\text { 5322, 53220, 53221, 5330, 53300, 53301, 5332, 53320, 53321, 5340, 53400, 53401, 5342, 53420, 53421, 5693, 578, } \\
\quad \text { 5780, 5781, and 5789 } \\
\text { Hemorrhagic stroke: } 430,431,432,4320,4321,4329 \text {, and } 99702 \\
\text { Iatrogenic postoperative bleed: } 99811 \\
\text { Blood transfusion: } 9902,9903 \text {, and } 9904\end{array}$ \\
\hline
\end{tabular}


TABLE E2. Definitions of baseline characteristics

Baseline characteristic

Arteriovenous malformation

Atrial fibrillation

Cancer
International Classification of Diseases, Ninth Revision, Clinical Modification (ICD-9-CM) diagnosis/ procedure codes

Diagnosis codes (from index and prior admissions): 74781 and 74782

Diagnosis codes (from index and prior admissions): 4273, 42731, and 42732

Diagnosis codes (from index and prior admissions): 1400, 1401, 1403, 1404, 1405, 1406, 1408, 1409, 1410, $1411,1412,1413,1414,1415,1416,1418,1419,1420,1421,1422,1428,1429,1430,1431,1438,1439$, $1440,1441,1448,1449,1450,1451,1452,1453,1454,1455,1456,1458,1459,1460,1461,1462,1463$, $1464,1465,1466,1467,1468,1469,1470,1471,1472,1473,1478,1479,1480,1481,1482,1483,1488$, 1489, 1490, 1491, 1498, 1499, 1500, 1501, 1502, 1503, 1504, 1505, 1508, 1509, 1510, 1511, 1512, 1513, $1514,1515,1516,1518,1519,1520,1521,1522,1523,1528,1529,1530,1531,1532,1533,1534,1535$, $1536,1537,1538,1539,154,1540,1541,1542,1543,1548,1550,1551,1552,156,1560,1561,1562,1568$, $1569,157,1570,1571,1572,1573,1574,1578,1579,158,1580,1588,1589,159,1590,1591,1598,1599$, $1600,1601,1602,1603,1604,1605,1608,1609,1610,1611,1612,1613,1618,1619,1620,1622,1623$, $1624,1625,1628,1629,1630,1631,1638,1639,1640,1641,1642,1643,1648,1649,1650,1658,1659$, $1700,1701,1702,1703,1704,1705,1706,1707,1708,1709,171,1710,1712,1713,1714,1715,1716$, $1717,1718,1719,1720,1721,1722,1723,1724,1725,1726,1727,1728,1729,1730,17300,17301$, $17302,17309,1731,17310,17311,17312,17319,1732,17320,17321,17322,17329,1733,17330,17331$, 17332, 17339, 1734, 17340, 17341, 17342, 17349, 1735, 17350, 17351, 17352, 17359, 1736, 17360, 17361, 17362, 17369, 1737, 17370, 17371, 17372, 17379, 1738, 17380, 17381, 17382, 17389, 1739, 17390, 17391, $17392,17399,174,1740,1741,1742,1743,1744,1745,1746,1748,1749,1750,1759,1760,1761,1762$, $1763,1764,1765,1768,1769,179,180,1800,1801,1808,1809,181,1820,1821,1828,1830,1832,1833$, $1834,1835,1838,1839,184,1840,1841,1842,1843,1844,1848,1849,185,1860,1869,1871,1872,1873$, $1874,1875,1876,1877,1878,1879,1880,1881,1882,1883,1884,1885,1886,1887,1888,1889,1890$, 1891, 1892, 1893, 1894, 1898, 1899, 1900, 1901, 1902, 1903, 1904, 1905, 1906, 1907, 1908, 1909, 1910, 1911, 1912, 1913, 1914, 1915, 1916, 1917, 1918, 1919, 192, 1920, 1921, 1922, 1923, 1928, 1929, 193, 1940, 1941, 1943, 1944, 1945, 1946, 1948, 1949, 1950, 1951, 1952, 1953, 1954, 1955, 1958, 1960, 1961, 1962 , 1963, 1965, 1966, 1968, 1969, 197, 1970, 1971, 1972, 1973, 1974, 1975, 1976, 1977, 1978, 198, 1980, 1981, 1982, 1983, 1984, 1985, 1986, 1987, 19881, 19882, 19889, 1990, 1991, 1992, 2000, 20000, 20001, 20002 , 20003, 20004, 20005, 20006, 20007, 20008, 2001, 20010, 20011, 20012, 20013, 20014, 20015, 20016, 20017, 20018, 2002, 20020, 20021, 20022, 20023, 20024, 20025, 20026, 20027, 20028, 2003, 20030, 20031, 20032, 20033, 20034, 20035, 20036, 20037, 20038, 2004, 20040, 20041, 20042, 20043, 20044, 20045, 20046, 20047, 20048, 2005, 20050, 20051, 20052, 20053, 20054, 20055, 20056, 20057, 20058, 2006, 20060, 20061, 20062, 20063, 20064, 20065, 20066, 20067, 20068, 2007, 20070, 20071, 20072 , 20073, 20074, 20075, 20076, 20077, 20078, 2008, 20080, 20081, 20082, 20083, 20084, 20085, 20086, 20087, 20088, 201, 2010, 20100, 20101, 20102, 20103, 20104, 20105, 20106, 20107, 20108, 2011, 20110, 20111, 20112, 20113, 20114, 20115, 20116, 20117, 20118, 2012, 20120, 20121, 20122, 20123, 20124, 20125, 20126, 20127, 20128, 2014, 20140, 20141, 20142, 20143, 20144, 20145, 20146, 20147, 20148 , 2015, 20150, 20151, 20152, 20153, 20154, 20155, 20156, 20157, 20158, 2016, 20160, 20161, 20162, 20163, 20164, 20165, 20166, 20167, 20168, 2017, 20170, 20171, 20172, 20173, 20174, 20175, 20176, 20177, 20178, 2019, 20190, 20191, 20192, 20193, 20194, 20195, 20196, 20197, 20198, 202, 2020, 20200 , 20201, 20202, 20203, 20204, 20205, 20206, 20207, 20208, 2021, 20210, 20211, 20212, 20213, 20214 , 20215, 20216, 20217, 20218, 2022, 20220, 20221, 20222, 20223, 20224, 20225, 20226, 20227, 20228, 2023, 20230, 20231, 20232, 20233, 20234, 20235, 20236, 20237, 20238, 2024, 20240, 20241, 20242 , 20243, 20244, 20245, 20246, 20247, 20248, 2025, 20250, 20251, 20252, 20253, 20254, 20255, 20256, 20257, 20258, 2026, 20260, 20261, 20262, 20263, 20264, 20265, 20266, 20267, 20268, 2027, 20270, 20271, 20272, 20273, 20274, 20275, 20276, 20277, 20278, 2028, 20280, 20281, 20282, 20283, 20284, 20285, 20286, 20287, 20288, 2029, 20290, 20291, 20292, 20293, 20294, 20295, 20296, 20297, 20298, 203, 2030, 20300, 20301, 20302, 2031, 20310, 20311, 20312, 2038, 20380, 20381, 20382, 204, 2040, 20400, 20401, 20402, 2041, 20410, 20411, 20412, 2042, 20420, 20421, 20422, 2048, 20480, 20481, 20482, 2049, 20490, 20491, 20492, 205, 2050, 20500, 20501, 20502, 2051, 20510, 20511, 20512, 2052, 20520, 20521, 20522, 2053, 20530, 20531, 20532, 2058, 20580, 20581, 20582, 2059, 20590, 20591, 20592, 206, 2060, 20600, 20601, 20602, 2061, 20610, 20611, 20612, 2062, 20620, 20621, 20622, 2068, 20680, 20681, 20682, 2069, 20690, 20691, 20692, 207, 2070, 20700, 20701, 20702, 2071, 20710, 20711, 20712, 2072, 20720, 20721, 20722, 2078, 20780, 20781, 20782, 208, 2080, 20800, 20801, 20802, 2081, 20810, 20811, 20812, 2082, 20820, 20821, 20822, 2088, 20880, 20881, 20882, 2089, 20890, 20891, 20892, 20900, 20901, 20902,

(Continued) 
TABLE E2. Continued

Baseline characteristic

Cerebrovascular disease

Chronic obstructive pulmonary disease

Coagulopathy

Coronary artery disease

Deep vein thrombosis

Deep vein thrombosis, ileofemoral

Heart failure
Hypercoagulable state

International Classification of Diseases, Ninth Revision, Clinical Modification (ICD-9-CM) diagnosis/ procedure codes

20903, 20910, 20911, 20912, 20913, 20914, 20915, 20916, 20917, 20920, 20921, 20922, 20923, 20924 20925, 20926, 20927, 20929, 20930, 20931, 20932, 20933, 20934, 20935, 20936, 20970, 20971, 20972, 20973, 20974, 20975, 20979, 2300, 2301, 2302, 2303, 2304, 2305, 2306, 2307, 2308, 2309, 2310, 2311, $2312,2318,2319,2320,2321,2322,2323,2324,2325,2326,2327,2328,2329,2330,2331,2332,2333$, 23330, 23331, 23332, 23339, 2334, 2335, 2336, 2337, 2339, 2340, 2348, 2349, 25801, 25802, 25803, 51181, 78951, 7950, 79501, 79502, 79503, 79504, 79506, 7951, 79510, 79511, 79512, 79513, 79514, 79516, 79670, 79671, V1000, V1001, V1002, V1003, V1004, V1005, V1006, V1007, V10009, V1011, V1012, V1020, V1021, V1022, V1029, V103, V1040, V1041, V1042, V1043, V1044, V1045, V1046, V1047, V1048, V1049, V1050, V1051, V1052, V1053, V1059, V1060, V1061, V1062, V1063, V1069, V1071, V1072, V1079, V1081, V1082, V1083, V1084, V1085, V1086, V1087, V1088, V1089, V109, V1090, V1091, and V711

Diagnosis codes (from index and prior admissions): 3466, 34660, 34661, 34662, 34663, 3623, 36230, 36231, 36232, 36233, 36234, 36235, 36236, 36237, 430, 431, 432, 4320, 4321, 4329, 433, 4330, 43300, 43301, 4331, 43310, 43311, 4332, 43320, 43321, 4333, 43330, 43331, 4338, 43380, 43381, 4339, 43390, 43391, 434, 4340, 43400, 43401, 4341, 43410, 43411, 4349, 43490, 43491, 435, 4350, 4351, 4352, 4353, 4358, $4359,436,437,4370,4371,4372,4373,4374,4375,4376,4377,4378,4379,438,4380,4381,43810$, $43811,43812,43813,43814,43819,4382,43820,43821,43822,4383,43830,43831,43832,4384,43840$, $43841,43842,4385,43850,43851,43852,4386,4387,4388,43881,43882,43883,43884,43885,43889$, and 4389

Diagnosis codes (from index and prior admissions): 403, 4030, 40300, 40301, 4031, 40310, 40311, 4039, 40390, 40391, 404, 4040, 40400, 40401, 40402, 40403, 4041, 40410, 40411, 40412, 40413, 4049, 40490, 40491, 40492, 40493, 582, 5820, 5821, 5822, 5824, 5828, 58281, 58289, 5829, 583, 5830, 5831, 5832, $5834,5836,5837,5838,58381,58389,5839,585,5851,5852,5853,5854,5855,5856,5859,586,587,588$, 5880, 5881, 5888, 58881, 58888, 5889, V420, V56, V560, V561, V562, V563, V5631, V5632, V568, V451, V4511, and V4512

Diagnosis codes (from index and prior admissions): 491, 4910, 4911, 4912, 49120, 49121, 49122, 4918, 4919 , 492, 4920, 4928, 493, 4930, 49300, 49301, 49302, 4931, 49310, 49311, 49312, 4932, 49320, 49321, 49322, 4938, 49380, 49381, 49382, 4939, 49390, 49391, 49392, 494, 4940, 4941, and 496

Diagnosis codes (from index and prior admissions): 286, 2860, 2861, 2862, 2863, 2864, 2865, 2866, 2867 , 2869, 2841, 2871, 2873, 28730, 28731, 28732, 28733, 28739, 2874, 2875, 2878, 2879, and 28984

Diagnosis codes (from index and prior admissions): 410, 4100, 41000, 41001, 41002, 4101, 41010, 41011, 41012, 4012, 40120, 41021, 41022, 4103, 41030, 41031, 41032, 4104, 41040, 41041, 41042, 4105, 41050, $41051,41052,4106,41060,41061,41062,4107,41070,41071,41072,4108,41080,41081,41082,4109$, 41090, 41091, 41092, 411, 4110, 4111, 4118, 41181, 41189, 412, 413, 4130, 4131, 4139, 414, 4140, 41400, 41401, 41402, 41403, 41404, 41405, 41406, 41407, 4142, 4143, 4144, 4295, 4296, 4297, 42971, 42979, V4581, and V4582

Diabetes Diagnosis codes (from index and prior admissions): 249, 2490, 24900, 24901, 2491, 24910, 24911, 2492, 24920, 24921, 2493, 24930, 24931, 2494, 24940, 24941, 2495, 24950, 24951, 2496, 24960, 24961, 2497, 24970, 24971, 2498, 24980, 24981, 2499, 24990, 24991, 250, 2500, 25000, 25001, 25002, 25003, 2501, $25010,25011,25012,25013,2502,25020,25021,25022,25023,2503,25030,25031,25032,25033,2504$, $25040,25041,25042,25043,2505,25050,25051,25052,25053,2506,25060,25061,25062,25063,2507$, 25070, 25071, 25072, 25073, 2508, 25080, 25081, 25082, 25083, 2509, 25090, 25091, 25092, and 25093

Diagnosis codes (from index and prior admissions): 4511, 45111, 45118, 45119, 4512, 45181, 45183, 45184, $45189,4519,452,4530,4531,4532,4533,4534,45340,45341,45342,4538,4539,6713,67130,67131$, $67133,6714,67140,67141,67142,67144,6715,67150,67151,67152,67153,67154$, and 6719

Diagnosis codes (from index and prior admissions): 45111, 45181, and 45341

Diagnosis codes (from index and prior admissions): 39891, 428, 4280, 4281, 4282, 42820, 42821, 42822, 42823, 4283, 42830, 42831, 42832, 42833, 4284, 42840, 42841, 42842, 42843, 4289, 429, 4290, 4291, 4292, 4293, 4294, 4295, 4296, 4297, 42971, 42979, 4298, 42981, 42982, 42983, 42989, and 4299

Diagnosis codes (from index and prior admissions): 28653, 28981, and 28982 


\begin{tabular}{|c|c|}
\hline Baseline characteristic & $\begin{array}{c}\text { International Classification of Diseases, Ninth Revision, Clinical Modification (ICD-9-CM) diagnosis/ } \\
\text { procedure codes }\end{array}$ \\
\hline Hypertension & $\begin{array}{l}\text { Diagnosis codes (from index and prior admissions): 401, 4010, 4011, 4019, 402, 4020, 4021, 4029, 40290, } \\
\text { 40291, 403, 4030, 40300, 40301, 4031, 40310, 40311, 4039, 40390, 40391, 404, 4040, 40400, 40401, } \\
\text { 40402, 40403, 4041, 40410, 40411, 40412, 40413, 4049, 40490, 40491, 40492, 40493, 405, 4050, 4050, } \\
\text { 40509, 4051, 40511, 40519, 4059, 40591, 40599, and 4372 }\end{array}$ \\
\hline Major bleeding & $\begin{array}{l}\text { Diagnosis codes (from index and prior admissions): } 4230,4233,430,431,432,4320,4321,4329,4560, \\
\text { 45620, } 53021,53082,5310,53100,53101,5312,53120,53121,5320,53200,53201,5322,53220,53221, \\
5330,53300,53301,5332,53320,53321,5340,53400,53401,5342,53420,53421,5963,578,5780,5781, \\
5789,5997,59970,59971,59972,7191,5847,7848,7863,78630,78639 \text {, and } 99811\end{array}$ \\
\hline Ischemic stroke & $\begin{array}{l}\text { Diagnosis codes (from index and prior admissions): 43301, 43311, 43321, 43331, 43381, 43391, 43401, } \\
\text { 43411, 43491, and } 99702\end{array}$ \\
\hline Liver cirrhosis & Diagnosis codes (from index and prior admissions): 5712, 5715, and 5716 \\
\hline Surgery & 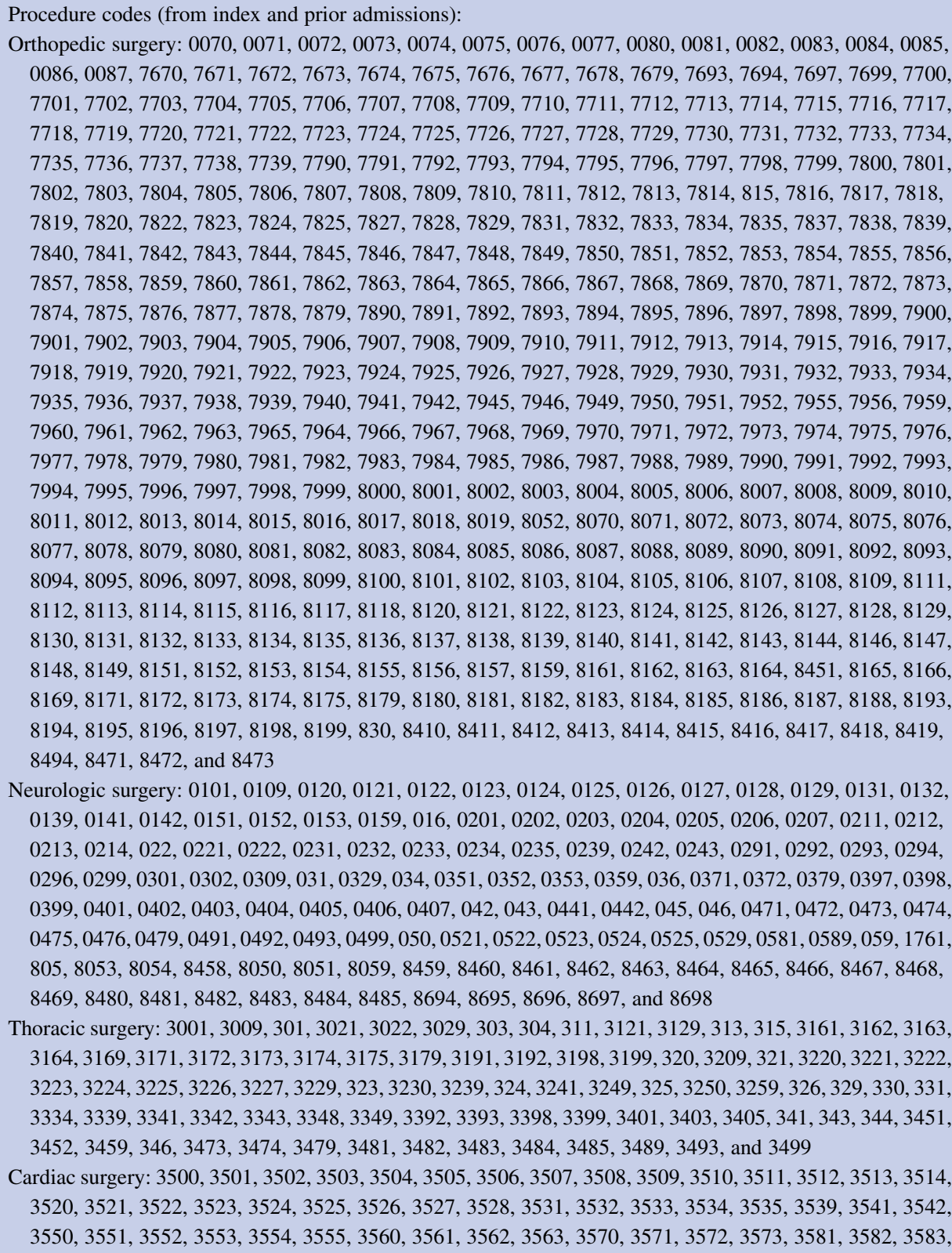 \\
\hline
\end{tabular}

(Continued) 
TABLE E2. Continued

\begin{tabular}{|c|c|}
\hline Baseline characteristic & $\begin{array}{c}\text { International Classification of Diseases, Ninth Revision, Clinical Modification (ICD-9-CM) diagnosis/ } \\
\text { procedure codes }\end{array}$ \\
\hline & 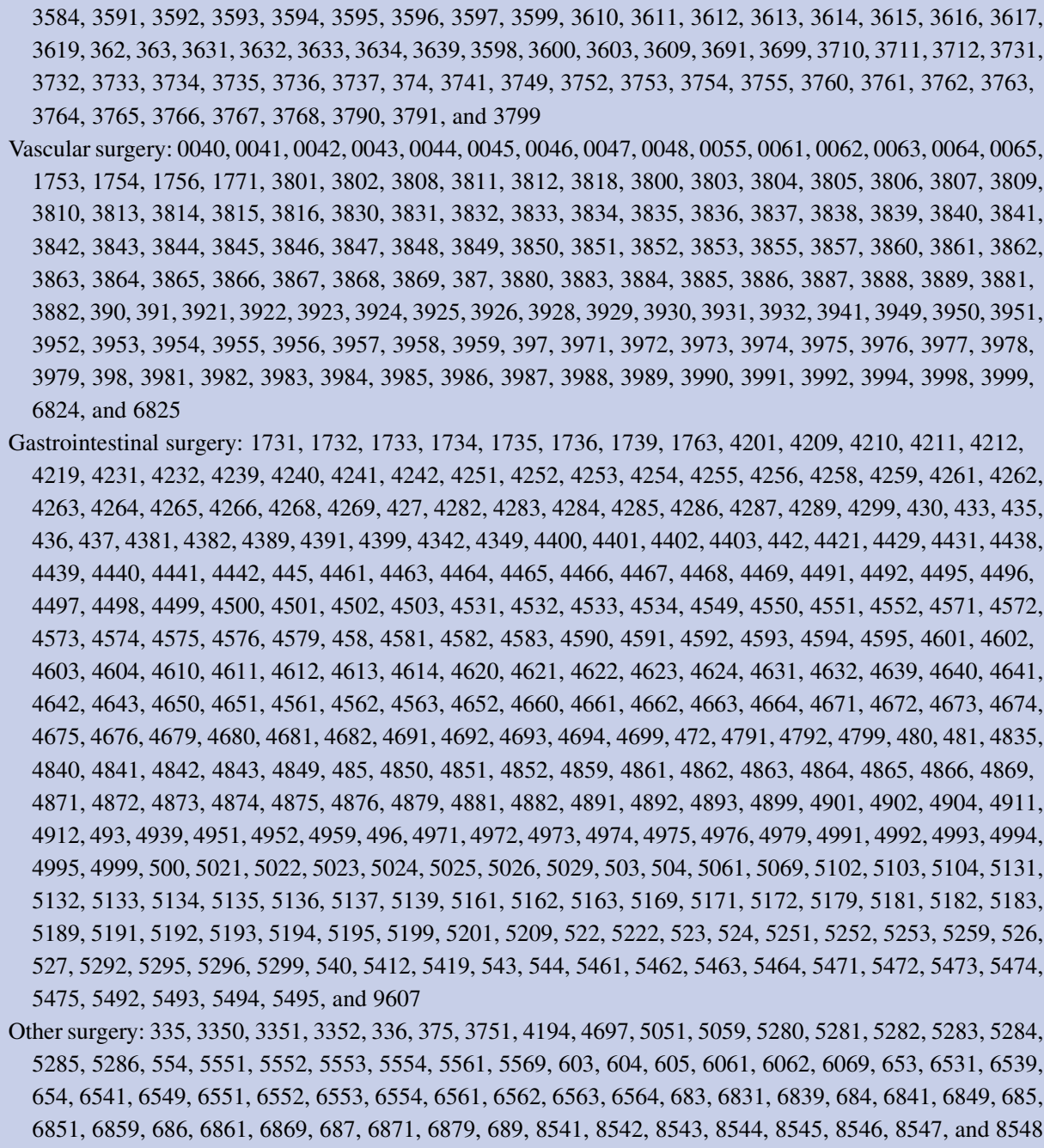 \\
\hline Trauma & $\begin{array}{l}\text { Diagnosis codes (from index and prior admissions): 80000, 80001, 80002, 80003, 80004, 80005, 80006, } \\
80009,80050,80051,80052,80053,80054,80055,80056,80059,80100,80101,80102,80103,80104, \\
80105,80106,80109,80150,80151,80152,80153,80154,80155,80156,80159,8020,8021,80220, \\
80221,80222,80223,80224,80225,80226,80227,80228,80229,80230,80231,80232,80233,80234, \\
80235,80236,80237,80238,80239,8024,8025,8026,8027,8028,8029,80300,80301,80302,80303, \\
80304,80305,80306,80309,80350,80351,80352,80353,80354,80355,80356,80359,80400,80401, \\
80402,80403,80404,80405,80406,80409,80450,80451,80452,80453,80454,80455,80456,80459, \\
82000,82001,82002,82003,82009,82010,82011,82012,82013,82019,82020,82021,82022,82030, \\
82031,82032,8208,8209,82100,82101,82110,82111,82120,82121,82122,82123,82129,82130, \\
82131,82132,82133,82139,8220,8221,82300,82301,82302,82310,82311,82312,82320,82321, \\
82322,82330,82331,82332,82340,82341,82342,82380,82381,82382,82390,82391,82392,8240, \\
8241,8242,8243,8244,8245,8246,8247,8248,8249,8250,8251,82520,82521,82522,82523,82524, \\
82525,82529,82530,82531,82532,82533,82534,82535,82539,8260,8261,8270,8271,9050,9053, \\
9054, \text { V5412, V5415, V5416, V5242, V5413, V5423, V5425, and V5426 }\end{array}$ \\
\hline $\begin{array}{l}\text { Patent foramen ovale or atrial } \\
\text { septal defect }\end{array}$ & $\begin{array}{l}\text { Diagnosis codes (from index, prior, or future admissions): } 7455 \text { and } 74561 \\
\text { Procedure codes (from index or future admissions): } 3551,3552,3561 \text {, and } 3571\end{array}$ \\
\hline
\end{tabular}


TABLE E2. Continued

\begin{tabular}{ll}
\hline \multicolumn{1}{c}{ Baseline characteristic } & International Classification of Diseases, Ninth Revision, Clinical Modification (ICD-9-CM) diagnosis/ \\
procedure codes
\end{tabular}

TABLE E3. CONSORT style flow chart of patient inclusion and exclusion criteria for the study

\begin{tabular}{|c|c|c|c|c|c|}
\hline Inclusion criteria & $\begin{array}{l}\text { No. of patients } \\
\text { included }\end{array}$ & $\begin{array}{l}\% \text { of total } \\
\text { included }\end{array}$ & $\begin{array}{l}\text { No. of patients } \\
\text { excluded }\end{array}$ & $\begin{array}{l}\% \text { of total } \\
\text { excluded }\end{array}$ & Exclusion criteria \\
\hline \multirow{3}{*}{$\begin{array}{l}\text { Pulmonary embolism patients in New York } \\
\text { State, 1999-2013 }\end{array}$} & 174,322 & & & & \\
\hline & & & 66 & $0.0 \%$ & Age $<18$ y or missing \\
\hline & & & 6094 & $3.5 \%$ & Non-New York State residents \\
\hline \multirow{2}{*}{$\begin{array}{l}\text { Adult pulmonary embolism patients who are } \\
\text { New York State residents, } 1999-2013^{*}\end{array}$} & 168,166 & 96.5 & & & \\
\hline & & & 16,4061 & 94.1 & No reperfusion therapy \\
\hline \multirow{6}{*}{$\begin{array}{l}\text { Adult pulmonary embolism patients who underwent } \\
\text { thrombolysis and/or pulmonary embolectomy }\end{array}$} & 4105 & 2.4 & & & \\
\hline & & & 145 & 0.1 & Previous IVC filter \\
\hline & & & 13 & 0.0 & Previous pulmonary endarterectomy \\
\hline & & & 230 & 0.1 & Elective admission type \\
\hline & & & 1712 & 1.0 & $\begin{array}{l}\text { Primary diagnosis not pulmonary } \\
\text { embolism }\end{array}$ \\
\hline & & & 177 & 0.1 & Treated $>3 \mathrm{~d}$ after admission date \\
\hline Patients meeting all inclusion and exclusion criteria & 2111 & 1.2 & & & \\
\hline
\end{tabular}

IVC, Inferior vena cava. *Used to calculate incidence of pulmonary embolism in New York State. 
TABLE E4. Baseline patient characteristics of adult pulmonary embolism patients who were and were not reperfused

\begin{tabular}{|c|c|c|c|c|}
\hline Baseline characteristics & $\begin{array}{c}\text { Not reperfused } \\
(n=164,061)\end{array}$ & $\begin{array}{c}\text { Reperfused } \\
(n=4105)\end{array}$ & $P$ value & Std diff, $\%$ \\
\hline \multicolumn{5}{|l|}{ Demographics } \\
\hline Age, $y$, mean $\pm S D$ & $64.2 \pm 17.2$ & $58.5 \pm 16.9$ & $<.001$ & -33.5 \\
\hline Male sex, $n(\%)$ & $70,208(43)$ & $1912(47)$ & $<.001$ & 7.6 \\
\hline \multicolumn{5}{|l|}{ Race, n (\%) } \\
\hline White (non-Hispanic) & $104,220(64)$ & $2556(62)$ & .10 & -2.6 \\
\hline Black (non-Hispanic) & $28,618(17)$ & $751(18)$ & & 2.2 \\
\hline Hispanic & $20,112(12)$ & $260(6)$ & & -1.8 \\
\hline Other/unknown & $11,111(7)$ & $538(13)$ & & 2.6 \\
\hline Elective admission, $\mathrm{n}(\%)$ & $13,632(8)$ & $226(5)$ & $<.001$ & 11.1 \\
\hline \multicolumn{5}{|c|}{ Risk factors for pulmonary embolism, n (\%) } \\
\hline Past or present deep vein thrombosis & $56,150(34)$ & $1892(46)$ & $<.001$ & 24.4 \\
\hline Ileofemoral vein thrombosis & $21,103(13)$ & $994(24)$ & $<.001$ & 29.5 \\
\hline History of pulmonary embolism & $11,833(7)$ & $682(17)$ & $<.001$ & 29.3 \\
\hline Cancer & $51,917(32)$ & $932(23)$ & $<.001$ & -20.2 \\
\hline Major surgery or trauma, $<30 \mathrm{~d}$ & $50,591(31)$ & $715(17)$ & $<.001$ & -31.8 \\
\hline Major orthopedic surgery & $10,392(6)$ & $124(3)$ & $<.001$ & -15.7 \\
\hline Major nonorthopedic surgery & $42,190(26)$ & $580(14)$ & $<.001$ & -29.3 \\
\hline Major trauma & $5095(3)$ & $79(2)$ & $<.001$ & -7.6 \\
\hline Hypercoagulable state & $4363(3)$ & $220(5)$ & $<.001$ & 13.8 \\
\hline Two or more risk factors & $47,717(29)$ & $1204(29)$ & .73 & 0.5 \\
\hline \multicolumn{5}{|l|}{ Contraindications for thrombolysis, $\mathrm{n}(\%)$} \\
\hline Major bleeding, $<30 \mathrm{~d}$ & $10,096(6)$ & $286(7)$ & .033 & 3.3 \\
\hline Ischemic stroke, $<6$ mo & $3770(2)$ & $168(4)$ & $<.001$ & 10.2 \\
\hline Coagulopathy & $12,178(7)$ & $387(9)$ & $<.001$ & 7.2 \\
\hline Cerebrovascular disease & $14,187(9)$ & $363(9)$ & .66 & 0.7 \\
\hline Peripheral vascular disease & $5442(3)$ & $188(5)$ & $<.001$ & 6.5 \\
\hline Liver cirrhosis & $1618(1)$ & $32(1)$ & .18 & -2.2 \\
\hline \multicolumn{5}{|l|}{ Comorbidities, n (\%) } \\
\hline Coronary artery disease & $40,716(25)$ & $838(20)$ & $<.001$ & -10.5 \\
\hline Diabetes mellitus & $37,303(23)$ & $922(22)$ & .68 & -0.7 \\
\hline Hypertension & $95,893(58)$ & $2209(54)$ & $<.001$ & -9.4 \\
\hline Dyslipidemia & $50,019(30)$ & 1179 (29) & .015 & -3.9 \\
\hline Congestive heart failure & $33,278(20)$ & $884(22)$ & .049 & 3.1 \\
\hline Atrial fibrillation & $23,022(14)$ & $497(12)$ & $<.001$ & -5.7 \\
\hline Chronic obstructive airway disease & $44,711(27)$ & $880(21)$ & $<.001$ & -13.6 \\
\hline Chronic kidney disease & $16,975(10)$ & $409(10)$ & .43 & -1.3 \\
\hline
\end{tabular}


TABLE E5. Sensitivity analysis of outcomes with and without adjustment for hospital

\begin{tabular}{|c|c|c|c|c|}
\hline \multirow[b]{3}{*}{ Adjustment hierarchy* } & \multicolumn{4}{|c|}{ Thrombolysis vs surgery } \\
\hline & \multicolumn{2}{|c|}{ 30-d mortality } & \multicolumn{2}{|c|}{ 5-y survival } \\
\hline & OR $(95 \%$ CI $)$ & $P$ value & HR $(95 \%$ CI $)$ & $P$ value \\
\hline Patient & $1.12(0.72-1.73)$ & .62 & $1.11(0.83-1.49)$ & .48 \\
\hline Patient and hospital & $1.34(0.78-2.27)$ & .14 & $1.18(0.81-1.72)$ & .39 \\
\hline \multicolumn{5}{|c|}{$\begin{array}{l}O R \text {, Odds ratio; } C I \text {, confidence interval; } H R \text {, hazard ratio. *Adjustment for patient characteristics was done via logistic regression and Cox modeling for } 30 \text {-day mortality and } 5 \text { - } \\
\text { year survival, respectively, with all patient demographics and baseline characteristics entered as covariates into initial model, and covariates in the final model determined via } \\
\text { stepwise selection with } P=.25 \text { for entry into the model and } P=.15 \text { to stay in the model. If reperfusion type was not a significant covariate, it was forced into the final model. } \\
\text { Adjustment for patient characteristics and hospital was done via hierarchical logistic regression and Cox modeling for 30-day mortality and 5-year survival, respectively, with all } \\
\text { patient demographics, baseline characteristics, and whether the hospital had cardiac surgery capability (as defined by the New York State Annual Cardiac Surgery Reports; https:// } \\
\text { www.health.ny.gov/statistics/diseases/cardiovascular/) entered as covariates into the initial model, and covariates in the final model determined via stepwise selection with } \\
P=.25 \text { for entry into the model and } P=.15 \text { to stay in the model. If reperfusion type or cardiac surgery center was not included as a significant covariate, it was forced into } \\
\text { the final model. }\end{array}$} \\
\hline
\end{tabular}

TABLE E6. Significant predictors of cumulative incidence of recurrent pulmonary embolism up to 5 years after reperfusion

\begin{tabular}{|c|c|c|c|c|}
\hline \multirow[b]{2}{*}{ Predictor } & \multicolumn{2}{|c|}{ All recurrent $\mathbf{P E}$} & \multicolumn{2}{|c|}{ Recurrent PE necessitating inpatient readmission } \\
\hline & HR $(95 \%$ CI $)$ & $P$ value & HR $(95 \%$ CI $)$ & $P$ value \\
\hline Thrombolysis vs surgery & $0.88(0.64-1.21)$ & .43 & $3.38(1.48-7.73)$ & .005 \\
\hline IVC filter & $0.93(0.74-1.72)$ & .55 & $0.77(0.053-1.12)$ & .17 \\
\hline Patient age, 1-y interval & $0.99(0.98-0.99)$ & $<.001$ & $0.99(0.98-1.00)$ & .023 \\
\hline Procedure year, $1-y$ interval & $1.03(0.99-1.06)$ & .07 & $0.93(0.89-0.96)$ & $<.001$ \\
\hline History of DVT & $1.18(0.96-1.44)$ & .12 & & \\
\hline Cancer & $1.26(0.95-1.66)$ & .11 & & \\
\hline COPD & $1.28(1.00-1.63)$ & .052 & & \\
\hline History of PE & $1.36(1.04-1.76)$ & .024 & $1.69(1.12-2.55)$ & .007 \\
\hline Black vs white race & $1.36(1.07-1.74)$ & .013 & & \\
\hline Diabetes & & & $1.38(0.94-2.03)$ & .10 \\
\hline Cerebrovascular disease & $1.98(1.34-2.92)$ & $<.001$ & & \\
\hline Liver cirrhosis & $3.61(1.32-9.83)$ & .012 & $5.86(1.44-23.86)$ & .035 \\
\hline
\end{tabular}

Adjusted using logistic regression analysis, with all patient demographic data and baseline characteristics entered as covariates into initial model, and covariates in the final model determined via stepwise selection with $P=.25$ for entry into the model and $P=.15$ to stay in the model. $P E$, Pulmonary embolism; $H R$, hazard ratio; $C I$, confidence interval; $I V C$, inferior vena cava; $D V T$, deep vein thrombosis; $C O P D$, chronic obstructive pulmonary disease. 
TABLE E7. Significant predictors of long-term survival up to 5 years after reperfusion

\begin{tabular}{|c|c|c|c|c|}
\hline \multirow[b]{2}{*}{ Predictor } & \multicolumn{2}{|c|}{ Mortality, all patients } & \multicolumn{2}{|c|}{ Mortality, patients discharged alive } \\
\hline & HR $(95 \%$ CI $)$ & $P$ value & HR $(95 \%$ CI $)$ & $P$ value \\
\hline Recent surgery or trauma & & & $0.61(0.38-0.98)$ & .041 \\
\hline Procedure year, 1-y interval & & & $0.94(0.91-0.97)$ & $<.001$ \\
\hline IVC filter placement & $0.74(0.62-0.89)$ & .001 & $1.38(1.05-1.80)$ & .020 \\
\hline Dyslipidemia & $0.81(0.67-0.98)$ & .026 & & \\
\hline History of DVT & $0.83(0.70-0.99)$ & .044 & & \\
\hline Patient age, 1-y interval & $1.02(1.01-1.03)$ & $<.001$ & $1.02(1.01-1.03)$ & $<.001$ \\
\hline Thrombolysis vs surgery & $1.11(0.83-1.49)$ & .48 & $1.44(0.93-2.24)$ & .10 \\
\hline COPD & $1.26(1.04-1.53)$ & .020 & $2.03(1.55-2.67)$ & $<.001$ \\
\hline Atrial fibrillation & $1.28(1.01-1.62)$ & .044 & & \\
\hline $\mathrm{CHF}$ & $1.33(1.09-1.63)$ & .005 & & \\
\hline Chronic kidney disease & & & $1.55(1.06-2.29)$ & .026 \\
\hline Known coagulopathy & $1.36(1.05-1.79)$ & .022 & $1.40(0.93-2.09)$ & .10 \\
\hline Cerebrovascular disease & $1.79(1.34-2.40)$ & $<.001$ & $1.85(1.21-2.83)$ & .005 \\
\hline Peripheral vascular disease & & & $2.44(1.38-4.33)$ & .002 \\
\hline Cancer & $2.30(1.91-2.77)$ & $<.001$ & $5.19(3.97-6.78)$ & $<.001$ \\
\hline Liver cirrhosis & $3.39(1.66-6.91)$ & .001 & $4.33(1.53-12.22)$ & .006 \\
\hline
\end{tabular}

